\title{
El papel de la inmigración extranjera en el cambio social y urbano de el Besòs i el Maresme, un barrio periférico de Barcelona. Interrogaciones a partir de un estudio exploratorio
}

\section{The role of foreign immigration in the social and urban transformation in el Besòs i el Maresme, a high-rise suburb of Barcelona. Questions based on an exploratory study}

\author{
Naik Miret* y Pau Serra del Pozo**
}

\section{INTRODUCCIÓN}

Presentamos en este trabajo los resultados de un estudio exploratorio ${ }^{1}$ llevado a cabo en 2007-2009 en el barrio de El Besòs i el Maresme de Barcelona. En este barrio los extranjeros representan el 24\% de la población total en 2008 según datos padronales ${ }^{2}$, ocho puntos por encima de la media de la capital catalana. El Besòs i el Maresme pertenece a la primera corona del Área Metropolitana de Barcelona, símbolo del crecimiento urbano debido a la migración

\footnotetext{
* Universidad de Poitiers/Migrinter (CNRS). Francia (naik.miret@univ-poitiers.fr).

** Universitat Internacional de Catalunya. España (pserra@cir.uic.es).

${ }^{1}$ Hemos presentado una versión anterior de esta investigación en un congreso celebrado en Bordeaux en 2008 (Miret y Serra, 2008) y en el VI Congreso Nacional sobre las Migraciones en España en 2009. Esta versión se enriquece con los avances del programa IMITMA al cual participan los dos autores desde 2008 sobre la temática de la inserción de la migración andina en Barcelona -IMITMA: «Nuevas trayectorias de la migración internacional andina en América Latina y en Europa. Itinerarios de movilidad e inscripciones territoriales de los migrantes andinos en las grandes metrópolis en Argentina y España», CNRS/ CONICET-

${ }^{2}$ Con fecha 1 de enero de 2008, según el Instituto Nacional de Estadística.
} 
interna entre los años 1950 y 1970: «en aquella época los inmigrantes fueron realojados desde las puertas de entrada a los nuevos barrios obreros expresamente construidos para ellos en las periferias de las ciudades» (Algaba, 2003). La reciente dinámica de la migración extranjera en este barrio, y de manera general en este tipo de barrios populares españoles, lo convierte en un nuevo modelo de integración urbana, similar al modelo de países de más larga tradición migratoria. Este modelo de desconcentración residencial de los inmigrantes ya ha sido expuesto en varios trabajos en relación a las ciudades españolas (Bayona et al., 2004; Arbaci, 2008). Sin embargo las implicaciones concretas de esta desconcentración a escala de los mismos barrios es todavía un objeto de estudio poco conocido (González, et al. 2005).

Nos referimos a barrios reconocidos como «desfavorecidos» ${ }^{3}$ según la tipología utilizada por varios autores (Goñi, 2008), que sufrieron desde la crisis económica de los setenta procesos de degradación física y de marginación social (Tatjer, 2005). Estos territorios urbanos conocieron procesos de «filtrado inmobiliario» o filtering down ${ }^{4}$, que redujeron su calidad y atractivo y los hicieron asequibles a la población más desfavorecida, entre ella los inmigrantes extranjeros (Eseverri Mayer, 2010). Estos recién llegados —más jóvenes, activos y móviles - representan un gran potencial para la transformación de estos espacios. ¿Refuerzan la estructura de segregación urbana pre-existente o contribuyen a crear nuevos polos de «mezcla social» por el hecho de instalarse en ellas? Algunos autores (Colectivo IOE, 2006) hablan de «la oportunidad» que constituye la nueva inmigración internacional en España para los barrios que estaban hasta entonces en proceso de relegación social. Nosotros hemos hecho nuestra esta hipótesis. En este sentido, el barrio de el Besòs i el Maresme es representativo de las posibilidades de cambio de los polígonos de viviendas sociales en las afueras de Barcelona y de otras ciudades españolas.

Consideramos aquí el potencial de cambio en términos de desarrollo socioeconómico de las zonas urbanas, de vitalidad demográfica y también de la revitalización que pueden suponer los emprendedores étnicos: «los negocios regentados por personas de origen inmigrante, procedentes de países no co-

${ }^{3}$ Usamos aquí el término de «desfavorecido», el cual, aunque sea reductor de la riqueza y diversidad social y cultural de estos espacios, refleja claramente la concentración de realidades sociales y urbanísticas que necesitan ser mejoradas.

${ }^{4}$ Expresión de Homer Hoyt (1939). Antonio Algaba (2003) explica como «cuando se crea una vivienda nueva, un hogar se desplaza, liberando una vivienda usada que puede ser una alternativa para un hogar existente o "en proyecto". Según esta teoría, las viviendas reducen su calidad y su valor a medida que envejecen». 
munitarios, están transformando el contexto urbano y económico de nuestras ciudades» (Solé et al., 2007, p. 8). Serra (2006) ha tratado de mostrar efectos de revitalización urbana derivados de la implantación o reabertura desde la segunda mitad de los años 1990 de centenares de nuevos pequeños comercios dirigidos por emprendedores extranjeros en el distrito de Ciutat Vella de Barcelona, tras la crisis del comercio autóctono de la primera mitad de los 1990.

Enfoques similares han puesto de manifiesto el papel de los inmigrantes en la reactivación económica de las ciudades, como la success story de la inmigración en Miami (EE.UU.), una ciudad que experimentaba un estancamiento económico en los años 1950 y 1960 y que sufrió una gran transformación con la llegada de los cubanos (Portes y Stepick, 1993). Hoy Miami es el centro de negocios más importante de América Latina... situado en Estados Unidos (Beaverstock, 1999). Obviamente existe un cambio de escala espacial y temporal y de otras dimensiones entre Miami y Ciutat Vella y El Besòs i el Maresme que no permite abusar de las comparaciones. Sin embargo la presencia de un número importante de nuevos comercios y servicios, permite interrogarse sobre su capacidad de «revitalización», y este enfoque nos parece particularmente estimulante para cambiar la mirada sobre este tipo de barrio.

Existen numerosos casos de estudios de ciudades donde la llegada de inmigrantes ha supuesto una revitalización urbana, a través de las «centralidades étnicas», zonas urbanas donde se concentran numerosos negocios de emprendedores de origen extranjero. La tesis de la revitalización no es nuestra sino que procede de la literatura americana y se aplica no sólo al terreno urbano sino a otros aspectos sociales: Rumbaut (1999) ha destacado la «paradoja» de que los inmigrantes en los EE.UU., a pesar de las dificultades económicas que padecen, presentan resultados más favorables que los de los autóctonos en indicadores relativos a la salud materno-infantil y de los adolescentes, la educación de los adolescentes y la criminalidad, a causa de los hábitos o estilos de vida más saludables. Sin embargo la revitalización se presenta de manera prudente en nuestro caso de estudio de el Besòs i el Maresme tan solo como una hipótesis.

Estas preguntas nos parecen particularmente relevantes en el Besòs i el Maresme, teniendo en cuenta su contexto urbanístico diverso (figura 1) y con influencias contradictorias: se sitúa junto a una de las zonas urbanísticamente más dinámicas de la capital catalana —operaciones Forum 2004, Diagonal Mar y $22 @$ @ y —a la vez- cerca de los municipios al norte del continuo urbano del área metropolitana con los mas elevados porcentajes de población inmigrante — Santa Coloma de Gramenet y Badalona-. Al norte, sin solución de continuidad, limita con el emblemático barrio de La Mina —-municipio de 
FIGURA 1

DISTRITOS, BARRIOS Y VÍA

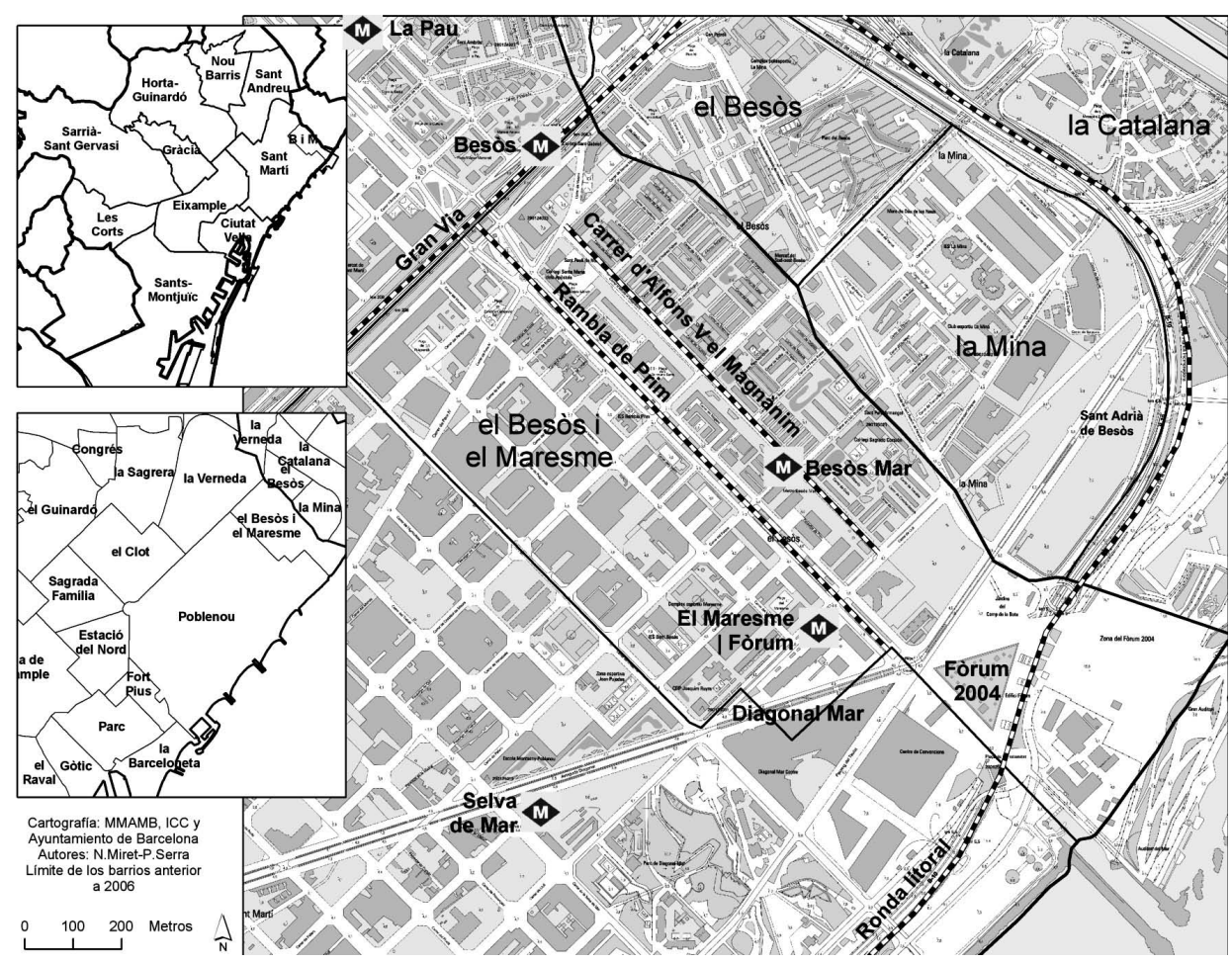

Fuente: elaboración propia a partir de Mancomunitat de Municipis de l'Àrea Metropolitana de Barcelona y Ajuntament de Barcelona.

Sant Adrià de Besòs-, de elevada proporción de población gitana, conocido en España por ser el símbolo del barrio desfavorecido, el cual está experimentando también un intenso proceso de renovación y rehabilitación urbanística. El Besòs i el Maresme nos parece un espacio urbano particularmente interesante de observar.

Nuestro trabajo persigue observar las interacciones entre diferentes factores de cambio urbano que influyen en el Besòs i el Maresme y el fenómeno de la inmigración extranjera. Nuestra postura geográfica se inscribe aquí en la línea mas reciente de las ciencias sociales en la cual, sin negar la fuerza de la inercia de las estructuras urbanas como resultado de procesos de dominación 
en el recorrido histórico, se incluye un enfoque constructivista, que considera cada elemento del sistema urbano como actor de una dinámica continua de cambio socio-espacial. La inmigración se observa aquí no solo como inscrita en un proceso segregativo - ya bien conocido a escala del Gran Barcelona (Fullaondo, 2008) - sino como un elemento entre los muchos actores y procesos que «fabrican» hoy en día la ciudad.

Por esta razón, nuestra postura necesita observar contextos y actores del cambio urbano a una escala micro, a partir de la observación minuciosa y del discurso de los actores. Nuestra metodología es fruto del carácter exploratorio de esta investigación y evolucionó con ella. En un primer momento nos acercamos a personas clave del barrio, como son los técnicos del ayuntamiento, miembros de los equipos pedagógicos de los establecimientos escolares o religiosos o personalidades de las asociaciones de vecinos ${ }^{5}$, entre los que realizamos seis entrevistas en profundidad. Todos valoraron la propuesta del estudio y enriquecieron nuestras hipótesis, como conocedores del espacio y de la sociedad del barrio, y como habitantes con su propia visión. A continuación, hicimos cuatro entrevistas en profundidad a inmigrantes recientes, pero que se integran en un conjunto de treinta entrevistas a migrantes recientes en otros barrios de la ciudad. Tres grupos de discusión informal en el instituto secundario a menores recién llegados en una aula de acogida, enriquecieron la cuestión de las representaciones espaciales y de las «maneras de habitar», particularmente interesantes en el caso de estos «nuevos habitantes» con experiencias urbanas anteriores muy diversas. Para terminar, siempre con el objetivo de explorar métodos y pistas para alcanzar el conjunto de nuestras hipótesis, realizamos una encuesta rápida en la calle ${ }^{6}$, que nos permitió «sondear» la población, cualquiera fuera su origen y antigüedad en el barrio. Utilizaremos estos elementos, conscientes de que son escasos, para analizar elementos de las territorialidades de la población extranjera y de sus interacciones con el barrio.

Cabe mencionar que este estudio no se continuó por razones de la propia investigación en común -IMITMA, ver nota al pie número 1 - pero que los materiales reunidos y el interés paradigmático de este barrio nos han llevado a formalizar los resultados, a pesar de su carácter exploratorio.

\footnotetext{
${ }^{5}$ Por razones de anonimato no mencionamos con más precisión los cargos de esas personas.

${ }^{6}$ Desarrollamos en mayo de 2009 un pequeño cuestionario sobre costumbres y desplazamientos cotidianos, pero solo pudimos sondear a 24 personas en dos días. Cabe mencionar que 13 habían nacido en el extranjero, 6 en otra región española y tan solo 5 en Barcelona. De las 24 personas, 16 vivían en el mismo barrio, las otras se encontraban en él por razones laborales o familiares. De las 16 personas residentes, 11 también trabajaban en el barrio.
} 
El Besòs i el Maresme, un barrio PerifÉrico popular en un CONTEXTO de CAMBIO URBANO

El barrio de el Besòs i el Maresme (figura 1) se encuentra ubicado en el distrito de Sant Martí, un antiguo suburbio de la periferia norte de Barcelona, anexado a la capital a finales del siglo XIX, que acogió durante un siglo actividades industriales - especialmente en el ámbito de almacenes de mercancías $\mathrm{y}$ transporte- $\mathrm{y}$ viviendas de trabajadores, usos que se van reduciendo desde el final de los años ochenta. Dentro del distrito, el barrio está delimitado al norte por el río Besòs, que subraya la «frontera» municipal de Barcelona; al sur, por la avenida Diagonal; al este, por el Mar Mediterráneo; y al oeste, por barrios de similares rasgos sociales y urbanísticos, como el de la Verneda y la Pau, o algo más antiguos como el de Clot y Camp de l'Arpa. Los municipios al norte, Sant Adrià de Besòs, adyacente, Santa Coloma de Gramenet y Badalona, contienen suburbios industriales y de viviendas de trabajadores más recientes que aparecen con la industrialización de los años 1960.

Por su posición y, sobre todo por su historia, El Besòs i el Maresme es un caso representativo de la morfología urbana de la periferia interior de Barcelona así como de los municipios de la periferia externa de la aglomeración. Su actual evolución es similar a la de muchos otros barrios periféricos catalanes y de las metrópolis españolas ${ }^{7}$.

\section{Industrialización y urbanización ${ }^{8}$}

El barrio nace a partir de la construcción de tres promociones de vivienda social entre 1956 y 1968 con el estilo de la arquitectura racionalista: Besòs (3.000 viviendas), la $\mathrm{Pau}^{9}$ (2.500 viviendas) y el Maresme ${ }^{10}$ (1.700 viviendas).

${ }^{7}$ Para el caso de Madrid ver la tesis de Cecilia Eseverri Mayer (2010) que, desde la perspectiva de la sociología de la juventud, nos da elementos de comprensión de las modalidades de la inserción de los inmigrantes extranjeros en este tipo de barrio.

${ }^{8}$ Buena parte de esta sección procede de Alberch, 2000.

9 Traducción catalana del «Grupo la Paz», nombre franquista original utilizado para conmemorar los «25 años de paz».

${ }^{10}$ La primera de las tres operaciones fue la del Besòs, especialmente construida para reubicar a los inmigrantes que ocuparon las barracas del barrio de Somorrostro, en la cercana playa del Poblenou. Una parte de las viviendas se reservará para los empleados de la empresa de transporte municipal al final de la construcción del complejo residencial. Sólo la tercera operación constituye un polígono de iniciativa privada, la Cooperativa del Sagrado Corazón, mientras que Besòs y la Pau fueron construidos por promotores públicos. 
Nacen, como en otros lugares en Europa, a partir de un crecimiento de la población sin precedentes en la metrópoli catalana, que aumentó en casi 700.000 personas en treinta años bajo el impulso de la migración interna, originaria principalmente de las regiones más pobres del sur de España. El barrio se divide en la década de 1960 a causa de la extensión de la «Gran Via», eje rápido que une el centro urbano barcelonés con su periferia y con los municipios del norte del área metropolitana, y que creó una barrera física y «mental».

La historia urbana de esta zona es común a muchos barrios de vivienda social en la capital catalana, construidos precipitadamente en detrimento de la calidad en un clima de especulación y de falta de control político. Inicialmente, estas zonas experimentaron un déficit de servicios y de equipamientos - escuelas, mercados, áreas deportivas, zonas verdes-y problemas de mantenimiento de los espacios públicos. Estos barrios también tienen en común el retraso de las infraestructuras de transporte: la estación «La Pau» de la línea 2 del metro, a casi 500 metros del extremo noroeste del barrio de el Besòs i el Maresme, no llegó hasta 1997. Su imagen también está marcada principalmente por los déficits arquitectónicos ${ }^{11}$, que ha sido la fuente de muchos conflictos entre asociaciones de vecinos y la administración desde la segunda mitad de los años setenta ${ }^{12}$. Estos problemas de gestión se han visto agravados por el hecho de que la mayoría de las viviendas sociales han pasado a ser propiedad de los residentes, que no disponen individualmente de recursos suficientes para resolver las deficiencias (Alberch, 2000).

\section{Una localización estratégica en la «nueva Barcelona»}

Los nuevos ayuntamientos democráticos desde 1979, junto con las reivindicaciones vecinales, han dado lugar a importantes transformaciones. El Besòs i el Maresme, así como otros barrios periféricos barceloneses, ha experimen-

11 Materiales de mala calidad que produjeron la famosa crisis del aluminosis que explica que parte de los apartamentos estén aun apuntalados en espera de poder pagar los arreglos, o la falta de ascensores.

12 En el barrio de el Besòs i el Maresme varias asociaciones lucharon para mejorar sus condiciones de vida con una implicación muy elevada de la población, movimiento social que confiere una identidad fuerte, en la tradición del movimiento reivindicativo federado por la FAVB (Federación de las Asociaciones de Vecinos de Barcelona) (Roca i Albert, 1994). 
tado un notable cambio, especialmente a principios de los años noventa, a partir de políticas urbanas de mejora de los espacios públicos y de los transportes públicos. Desde 1990, el eje principal de el Besòs i el Maresme, la Rambla Prim, aparece «como una de las más bellas ramblas» ${ }^{13}$ de Barcelona. Es una muestra de los esfuerzos para mejorar los espacios públicos (fotografía 1). A pocos metros, sin embargo, la calle de Alfons el Magnànim —antiguo rey de la Corona de Aragón, cuyo nombre pretende «ennoblecer» el barrio-, presenta en 2008 un aspecto más abandonado, con una menor presencia de comercios y un marco arquitectónico deteriorado (fotografía 2). En el sur, las calles del Maresme y del Treball, son espacios dedicados principalmente a vivienda y equipamientos — centros escolares y deportivos- y a almacenes re-

\section{FOTOGRAFÍA 1}

\section{LA RAMBLA PRIM EN EL BARRIO DE EL BESÒS I EL MARESME}

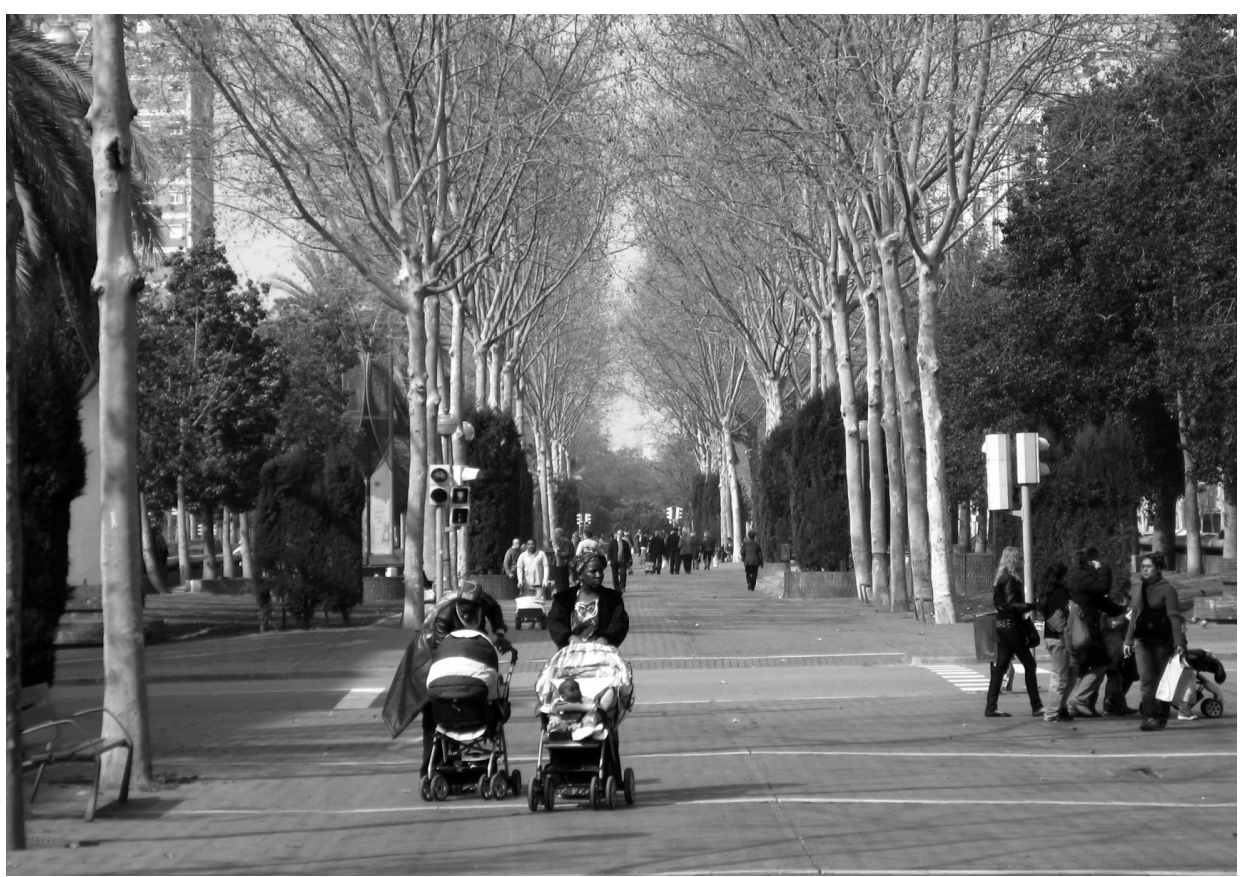

Fuente: los autores.

${ }^{13}$ Según la apreciación de Alberch (2000), el tipo de calle «rambla», que en catalán originalmente significa torrente, es emblemático de la identidad urbana catalana. 
FotograFía 2

«CENTRO COMERCIAL» EN LA CALLE DE ALFONS EL MAGNÀNIM, EN EL BARRIO DE EL BESÒS I EL MARESME

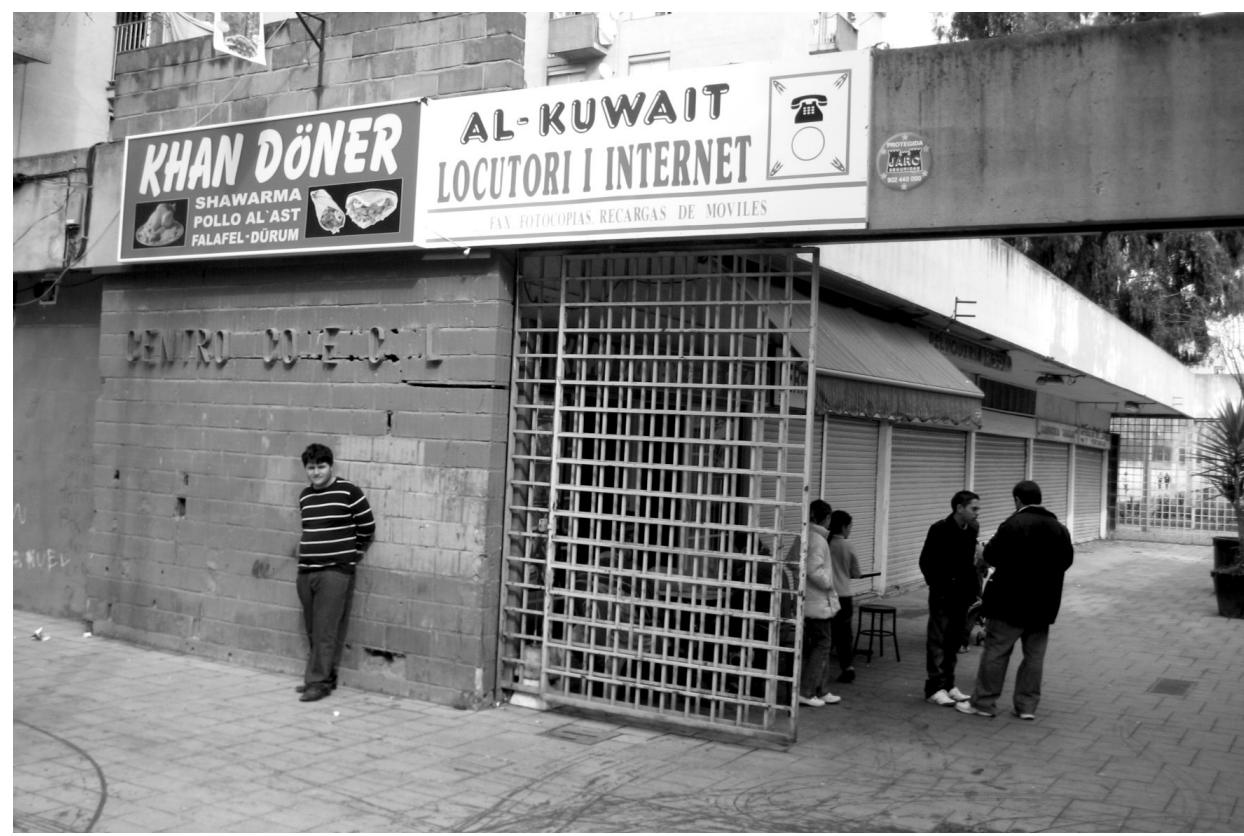

Fuente: los autores.

lacionados con el transporte, que mantienen la identidad industrial de esta área urbana.

Nuestra área de estudio también ha mejorado notablemente desde el punto de vista de la accesibilidad urbana. El metro, que llegó cerca del barrio en 1997, con la estación de La Pau, recientemente se ha vuelto a extender a las nuevas estaciones de Besòs y Besòs Mar, en la línea 4. El nuevo tranvía, que pasa por la calle Alfons el Magnànim, también ha permitido ampliar las conexiones con el transporte público metropolitano. El gobierno catalán y el ayuntamiento acordaron en marzo de 2009 llevar a cabo el proyecto de la «llei de barris» ${ }^{14}$ en nuestro barrio con 14 millones de euros de financiación, tanto

${ }^{14}$ Legislación aprobada en 2004 por el Parlamento de Cataluña para apoyar la inversión pública en espacios «de atención especial». 
para introducir mejoras de las casas, como en los espacios públicos y los equipamientos, en atención social y revitalización comercial. Esta política, ha permitido «un impulso increíble, con la reorganización integral de ciertas calles plazas y espacios públicos como la manzana entre Bernat Metge, Perpinyà, Llull i Alfons el Magnànim o la implantación de la recogida neumática de basura» (Diario El Periódico, 9 de abril de 2012).

Sin embargo el cambio urbano más espectacular es el que experimentó el entorno inmediato de nuestra área de estudio. Al final de la década de los noventa, la ampliación de la Diagonal — la avenida principal de la capital que la separa del resto de su distrito al sur-este-, dará nacimiento a un nuevo barrio «híper» moderno. Al sur de el Besòs i el Maresme, este «escaparate urbano» llamado «Diagonal Mar» completa uno de los extremos de la ciudad, además de transformar su imagen considerablemente con la construcción de edificios para convenciones, oficinas y viviendas en rascacielos - parque empresarial del Fórum 2004, frente marítimo remodelado, grandes hoteles y edificios de convenciones y un enorme centro comercial-. El contraste entre el Besòs i el Maresme y su vecino Poblenou, antiguo barrio obrero e industrial con el cual compartía vínculos culturales y sociales muy fuertes, es cada día más rotundo (ver fotografía 3). Poblenou, que empezó a regenerarse con la villa olímpica de los juegos del 92, se distancia cada día más de los barrios obreros para identificarse, a base de grandes inversiones urbanísticas ${ }^{15}$, con el conjunto de «Diagonal Mar» y lo que representa de la ciudad moderna y globalizada ${ }^{16}$.

Esta es la situación de las transformaciones urbanas, sociales y económicas en las zonas cercanas a el Besòs i el Maresme que merecen nuestra atención. En el modelo urbanístico de Barcelona la regeneración está diseñada como una herramienta para la transmisión de «metástasis» de la renovación urbana (Bohigas, 1985). Como tal, los barrios cerca de los principales proyectos urbanos deben observarse en términos de su potencial de transformación. Con este entorno en plena modernización, el Besòs i el Maresme debería presentar una evolución positiva por su capacidad de atracción.

15 Poblenou se está transformando en un distrito de actividades de tecnologías no contaminantes a través de un programa de renovación y de rehabilitación de parte del patrimonio industrial: es el llamado «Distrito 22@», donde en los próximos años se esperaba la creación de numerosos nuevos puestos de trabajo de personas altamente cualificadas

${ }^{16}$ Para una lectura crítica de esta nueva ordenación urbana, ver el libro de Manuel Delgado (2005), y sobre políticas de barrio —en concreto después de 1992_, el libro de la Federación de Asociaciones de Vecinos de Barcelona (FAVB, 2006). 


\section{FOTOGRAFÍA 3}

EL CONTACTO ENTRE EL BARRIO POPULAR DE EL BÉSOS I EL MARESME Y EL BARRIO «HIPERMODERNO» DEL FÒRUM 2004

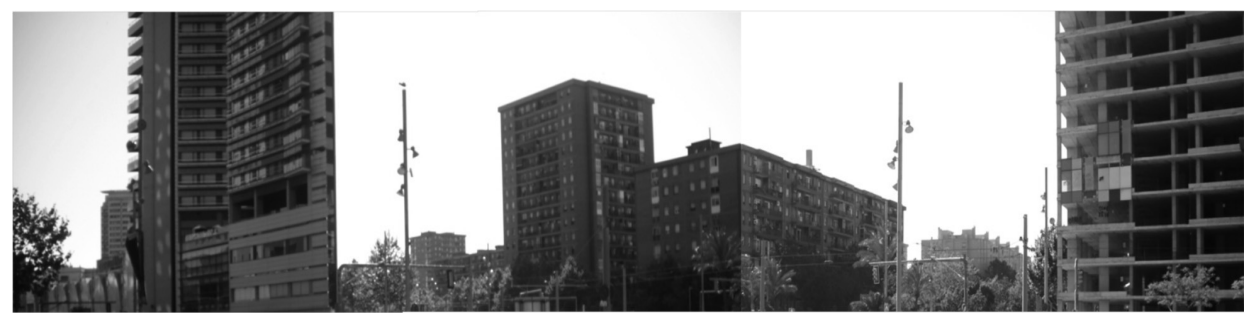

Fuente: los autores.

Ciertamente el barrio está adquiriendo una nueva «centralidad» urbana, y ha superado las graves carencias de décadas atrás. Pero también se puede observar, tal vez no en todas las partes del barrio, un proceso continuo de desvalorización a través del mercado de la vivienda.

UN «REFUGIO» RESIDENCIAL PARA LOS NUEVOS RESIDENTES EXTRANJEROS

La evolución del mercado de la vivienda es uno de los factores principales para explicar la llegada al barrio de los inmigrantes más pobres de los últimos años. Cabe señalar que en el contexto español la gran mayoría de las viviendas promovidas por las administraciones públicas se realizan bajo el régimen de tenencia de propiedad de la vivienda ${ }^{17}$. Esta especificidad determina un modelo de desarrollo bien diferente, por ejemplo, del de las cités en las banlieues francesas, que son zonas de viviendas públicas de alquiler, que vieron cambiar su poblamiento a partir de una movilidad residencial elevada a partir de los años setenta. Cuando la crisis económica de mitad de los años setenta empezó, sólo los más pobres de los habitantes de las cités francesas se quedaron, mientras que las clases obreras más establecidas, tanto autóctonas como inmigrantes, dejaron las cités y accedieron a la propiedad en casas unifamiliares de los suburbios residenciales. La oferta de viviendas de alquiler protegido quedó

17 «En España el parque de vivienda pública en alquiler se sitúa en el 1\% del total de las viviendas familiares primarias, la proporción más baja de los países europeos, después de Grecia» (Leal, 2002, p. 67). 
como una oportunidad para los inmigrantes más recientes y más desfavorecidos socialmente que aún no han tenido la oportunidad de salir de este parque de viviendas de las cités (Brun y Bonvalet, 2002), un proceso que se ajusta al filtering down, mencionado antes.

En 2002, Jesús Leal escribía, en referencia a las periferias urbanas españolas: «La inmigración afecta escasamente a estos barrios porque se trata de viviendas libres en propiedad, lo que dificulta el asentamiento de inquilinos en zonas de escasa movilidad residencial y de baja proporción de alquileres» (Leal, 2002, p. 67). Pero los primeros propietarios han envejecido o se trasladaron y han puesto estas viviendas a la venta: «...precisamente es esta elevada edad de los moradores autóctonos la que permite la aparición de un mercado de la vivienda en estos barrios ya compactados, bien por el fallecimiento, bien por traslado al hogar de otros familiares» (González Enríquez et al., 2005, p. 20). Así podemos afirmar que, desde comienzos de la presente década, el mercado inmobiliario residencial de este tipo de barrios se ha abierto más a la venta a los extranjeros.

En pocos años, esta parte del parque de vivienda ha cambiado de manos, y ha dado la oportunidad a los inmigrantes más estables, los que tenían trabajo y residencia regular, de desarrollar una estrategia residencial a partir de la adquisición de pisos baratos ${ }^{18}$ (Miret, 2009b). Estos pisos permiten cumplir con las exigencias legales para reagrupar a la familia, y constituyen una oportunidad, con la ayuda de los bancos - los cuales a partir de los años 2000 facilitaron préstamos hipotecarios a los extranjeros-, de mejorar una trayectoria residencial muchas veces muy precaria. Entre las personas encuestadas, solo a modo de tendencia, se puede mencionar que una mayoría llegó al barrio para agruparse con su familia, desde el extranjero o desde la misma ciudad (Barcelona) al momento del matrimonio o del nacimiento de un hijo. También es notable que la gran mayoría valore positivamente sus condiciones de vivienda actuales en el barrio. El motivo de la llegada al barrio por motivos de trabajo solo sucede después, para un reducido número de personas ${ }^{19}$.

Esta apertura del mercado inmobiliario combinado con la aceleración de la inmigración que ocurrió hasta la crisis económica, también ha podido generar situaciones de infravivienda en la medida en que se desarrollaron procesos es-

${ }^{18}$ La Encuesta Nacional de Inmigrantes (ENI) de 2007, realizada por el Instituto Nacional de Estadística (INE) muestra un aumento de la proporción de inmigrantes propietarios en España que constituyen ahora el $33 \%$.

${ }^{19}$ Encuesta propia, ver nota al pie 6. 
peculativos. Esta tendencia también ha sido facilitada por el aumento de la construcción en la gran corona metropolitana de Barcelona, en urbanizaciones de casas unifamiliares a las cuales accedieron parte de las clases medias que antiguamente se alojaban en el barrio. Se produce así una substitución residencial que concurre a bajar la media económica y de edad de los habitantes, donde cada vez más se alojan los jubilados, por una parte y, por otra parte, jóvenes familias de extranjeros ${ }^{20}$.

Sin embargo el barrio de el Besòs i el Maresme, como otros barrios de vivienda social españoles de similares características, no tiene un mercado inmobiliario uniforme: existe una franja de pisos de calidad media muy solicitados por parte de los hijos de los fundadores del barrio, muy arraigados a este territorio (Módenes, 2001), que prefieren quedarse, por ejemplo, en la revalorizada Rambla Prim. Se crean así contrastes muy importantes a escala de bloques de edificios, «micro segregaciones», que corresponden a la oposición entre bloques renovados y otros en espiral de degradación, donde los extranjeros más desfavorecidos han encontrado un mercado de vivienda atractivo (Terrones, 2008).

En definitiva encontramos en este barrio ingredientes de cambio social, a través de tres procesos: substitución residencial en el cual participan los inmigrantes, recualificación del entorno y rejuvenecimiento demográfico. Esto puede llevar a situaciones muy diferentes, desde la mejora del estatus del barrio a la relegación, si factores como la antigüedad de las zonas edificadas, el entorno físico — vías rápidas, industrias, almacenes... - o las características sociales de los nuevos residentes impiden continuar el proceso de revitalización. Vamos a describir algunos de estos procesos a continuación.

\section{Participación de los extranjeros en el proceso de cambio social}

La estructura del mercado de la vivienda descrita anteriormente explica que, de manera general en España, «estos barrios suelen presentar una serie de características sociales similares: hogares envejecidos, de clase trabajadora, con una elevada proporción de pensionistas y viudas y pocos hogares formados por jóvenes» (Leal, 2002, p. 68). La población extranjera ha participado en un proceso de sustitución de residentes de los primeros tiempos, en su mayoría

${ }^{20}$ Un proceso similar fue estudiado con detalle por Eseverri (Tesis Doctoral, 2010) en el barrio San Cristóbal de los Ángeles, situado en la periferia de la ciudad de Madrid. 
inmigrantes de otras regiones del Estado español que han liberado gradualmente sus hogares, por envejecimiento, retorno a sus regiones de origen o traslado a otras zonas de la región metropolitana, más atractivas. Con frecuencia en estos suburbios de vivienda social se ha producido también una disminución de la población en los últimos veinte años. El barrio de el Besòs i el Maresme conoció una reducción de sus efectivos demográficos, desde un máximo de 29.000 habitantes a mediados de los años 1980 a 24.571 personas en 2001, con un aumento lento a partir de 2002 (Ajuntament de Barcelona, 2006).

Otros factores sociales permiten ilustrar la evolución socioeconómica de la población de la zona (Ajuntament de Barcelona, 2006): casi un tercio de los habitantes del barrio son aún identificables en 2005 como inmigrantes internos que han nacido en otra región española, con ocho puntos porcentuales por encima de la media del municipio de Barcelona, y tienen ahora una edad avanzada. Esta diferencia se fue reduciendo, para llegar hoy en día al 22,7\% de nacidos en el resto de España, solo 3 puntos por encima de la media de Barcelona. Sólo el 59\% de todos los habitantes del barrio declaró en 2007 hablar catalán, a diferencia del $75 \%$ de la media municipal, lo que refleja no sólo una diferencia cultural, sino también social: «así, es manifiesto que numerosos barrios del área metropolitana de Barcelona mantienen su original especialización demográfica en función del lugar de nacimiento, poniendo de manifiesto las dificultades del éxito del proyecto migratorio por la impermeabilidad de la sociedad de acogida» (Algaba, 2003).

En efecto, como se ha observado en la literatura ${ }^{21}$, en Barcelona, los barrios de la inmigración interna se corresponden con los grupos sociales más desfavorecidos. El barrio el Besòs i el Maresme se enmarca en la categoría de barrio desfavorecido a muy desfavorecido descrita por Goñi (2008, p. 12). Este autor categoriza varias secciones del barrio el Besòs i el Maresme, justamente aquellas donde vive la mayoría extranjera, en el cluster 2 de su análisis, que agrupa las extensiones urbanas y polígonos de vivienda de baja calidad con superficies de los alojamientos reducidas y con una sobrerrepresentación del régimen de tenencia en propiedad, de elevadas tasas de desempleo, de analfabetismo, de población envejecida y de categorías profesionales menos cualificadas - $83 \%$ de la población activa de promedio en el cluster-. Según los datos publicados en un diagnóstico comunitario (Ajuntament de Barcelona, 2006) esto también se refleja si observamos determinadas variables del barrio en relación al pro-

${ }^{21}$ Para profundizar el estudio de la segregación de la migración interna en Cataluña, ver Botey (1986) y Solé (1981). 
medio barcelonés en términos de nivel de educación - $21 \%$ de personas sin estudios, sólo $12 \%$ en Barcelona-, tasa de desempleo - $17 \%$, sólo $12 \%$ en Barcelona-, y sobrerrepresentación de categorías de trabajadores no calificados - 43\% de la población activa, sólo un 26\% en Barcelona-. Evidentemente, con el gran cambio de población que ocurrió en los últimos años, estas tendencias han debido cambiar, y sería interesante ver cómo va evolucionar la composición social del barrio. Pero aquí nos interesa dar una imagen de cómo se situaba el barrio en el contexto de la metrópolis en el momento en que empieza a renovarse su población. Estos indicadores son utilizados para definir esta categoría urbana como «desfavorecida» en España (Alguacil Gómez, 2006). La desindustrialización ha afectado particularmente a estas poblaciones mayoritariamente obreras, quienes con la crisis han visto frenado su «ascensor» social. Esta concentración de dificultades se ve acentuada por una escasa movilidad residencial, ya que, al contrario de lo que ocurrió en este tipo de barrios en Francia, las mudanzas de el Besòs i el Maresme a otro barrio no son muy numerosas debido a que el elevado régimen de tenencia en propiedad que caracteriza el barrio - la tasa de propiedad es del $83 \%$, en contraste con el $68 \%$ en Barcelona (Ajuntament de Barcelona, 2006) — confiere a sus habitantes una cierta estabilidad. Estos propietarios vieron su entorno degradarse sin poder abandonar el barrio donde han invertido su capital inmobiliario, son residentes cautivos que sufren el proceso que en Francia se denomina assignation résidentielle, es decir que no tienen otra oferta residencial. Por eso aún se encuentra población envejecida entre los primeros vecinos del barrio.

En muchos barrios de Barcelona este envejecimiento fue compensado por una considerable inmigración extranjera. La metrópoli catalana ha acogido buena parte del crecimiento excepcional de la inmigración que se ha producido en España durante los últimos diez años. En 2010 en Barcelona residen 284.632 extranjeros, unos 10.000 menos que un año atrás, pero aún así supone casi diez veces más que en 1996 (29.000). Con el 1,8\% de todos los residentes extranjeros registrados en el municipio de Barcelona, 5.259 personas en 2010, el barrio de el Besòs i el Maresme no es el más representativo de la inmigración reciente. Pertenece, no obstante, al grupo que continuó creciendo hasta 2008, incluso cuando las estadísticas se ajustaron a la baja a partir de $2006^{22}$, como en otras ciudades de España; y tuvo la tasa más elevada de crecimiento de población extranjera entre 2007 y 2008, con un aumento del 22\%.

22 Disminución debido a la obligación para los extracomunitarios de realizar la renovación padronal a partir de 2006. 
Actualmente, la tasa de población extranjera del 25\% sigue siendo superior a la media de Barcelona en 2012, del 17,4\% (Ajuntament de Barcelona, 2012).

La reciente inmigración extranjera aparece, por tanto, claramente como un factor de renovación demográfica en nuestra área de estudio, proporcionando 4.700 nuevos residentes de 2000 a $2007^{23}$, así como en otros barrios periféricos de la capital catalana y municipios limítrofes del Área Metropolitana de Barcelona, que no han cesado de ganar población extranjera, mientras que la elección de residencia por la reciente inmigración en esos dos tipos de zonas era muy limitada hace diez años (Miret, 2009a).

La figura 2 muestra las secciones censales con mayor concentración residencial de extranjeros en el Área Metropolitana de Barcelona en 2008: en primer lugar, en determinadas zonas del municipio central, con porcentajes de población extranjera en relación a la total superiores al barrio de el Besòs i el Maresme -en el distrito de Ciutat Vella y en el Poble Sec, en el centro; y en Trinitat Vella y Ciutat Meridiana, en el norte-; a continuación, en determinados municipios cercanos del continuo urbano de Barcelona, tanto al norte - Badalona, Santa Coloma de Gramenet- como al sur — l'Hospitalet de Llobregat, Cornellà de Llobregat-.

La relativa desconcentración de los extranjeros hacia el área metropolitana de Barcelona se ha destacado anteriormente por otros autores (Domingo Valls et al., 2004) y se ha visto reforzada en los últimos años. Este proceso se puede explicar por la «saturación» de residentes extranjeros en el centro de la ciudad —algunas secciones llegan al 62\% de extranjeros-, en competencia por el espacio con la «gentrificación» urbanística y social (Sargatal, 2001). También se puede tener en cuenta la creciente integración de las redes sociales de los inmigrantes en las lógicas locales de acceso a una gama más amplia de vivienda. Esto lo muestra bien el ejemplo de los andinos que predominan en la ola más reciente de la inmigración en el área metropolitana. En otro estudio se destaca como los residentes de este origen, sobre todo por tener redes sociales muy activas, fueron los principales actores de la desconcentración metropolitana de la inmigración (Miret, 2009b).

En este contexto ${ }^{24}$, el barrio de el Besòs i el Maresme (figura 3) atrae también a varios grupos de inmigrantes. Los paquistaníes, 1.747 en 2008, forma-

${ }^{23}$ Usamos este último dato de 2007 porque después de esta fecha cambió la delimitación de los barrios en la estadística municipal.

${ }^{24}$ A continuación comentamos los datos referentes a 1 de enero de 2008, correspondientes al final del año —en el que finalizamos una parte estudio de campo-, e incluimos entre paréntesis el dato de 2012 —en el momento de redactar este artículo-. 
FIGURA 2

PORCENTAJE DE POBLACIÓN EXTRANJERA RESPECTO AL TOTAL DE LA POBLACIÓN TOTAL POR SECCIONES CENSALES EN EL ÁREA METROPOLITANA DE BARCELONA EN 2008

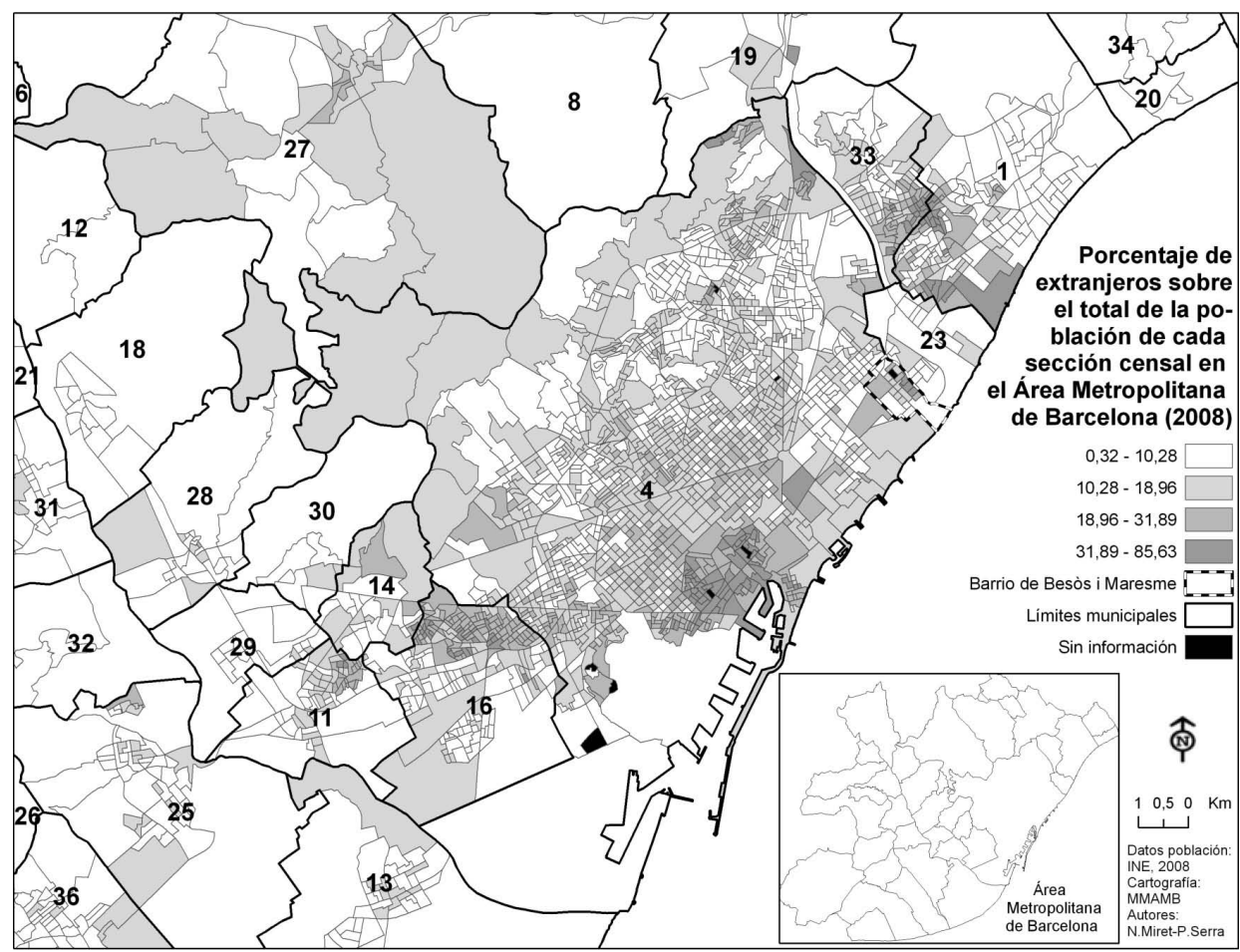

Municipios del Área Metropolitana de Barcelona: 1 Badalona; 2 Badia del Vallès; 3 Barberà del Vallès; 4 Barcelona; 5 Begues; 6 Castellbisbal; 7 Castelldefels; 8 Cerdanyola del Vallès; 9 Cervelló; 10 Corbera de Llobregat; 11 Cornellà de Llobregat; 12 el Papiol; 13 el Prat de Llobregat; 14 Esplugues de Llobregat; 15 Gavà; 16 l'Hospitalet de Llobregat; 17 la Palma de Cervelló; 18 Molins de Rei; 19 Montcada i Reixac; 20 Montgat; 21 Pallejà; 22 Ripollet; 23 Sant Adrià de Besòs; 24 Sant Andreu de la Barca; 25 Sant Boi de Llobregat; 26 Sant Climent de Llobregat; 27 Sant Cugat del Vallès; 28 Sant Feliu de Llobregat; 29 Sant Joan Despí; 30 Sant Just Desvern; 31 Sant Vicenç dels Horts; 32 Santa Coloma de Cervelló; 33 Santa Coloma de Gramenet; 34 Tiana; 35 Torrelles de Llobregat; 36 Viladecans.

Fuente: elaboración propia a partir de Instituto Nacional de Estadística (Datos Estadísticos) y Mancomunitat de Municipis de l’Àrea Metropolitana de Barcelona (Cartografía).

ban entonces el 28\% de los extranjeros del barrio, y ascendieron al 38\% en el último dato padronal (2.176 en 2012), reforzando mucho su posición en el barrio. Los chinos y los indios también están más presentes que en otros barrios barceloneses, aunque con tan sólo 248 personas y 150 en 2012 en el 
barrio, respectivamente. Los pakistaníes y los chinos se sitúan en el ranking de nacionalidades extranjeras en el caso de el Besòs i el Maresme en los lugares primero y cuarto respectivamente y en Barcelona en los lugares primero y tercero respectivamente en 2012. Este dominio asiático en el Besòs i el Maresme que queda bien reflejado en las distribuciones continentales en 2008 en la figura 3, es reforzado por los cercanos municipios de Sant Adrià de Besòs, Santa Coloma de Gramenet y Badalona como centros de atracción de inmigrantes de Asia en el área metropolitana (Miret, 2009a).

Después de los asiáticos, los ecuatorianos, los marroquíes, los andinos — por orden numérico Bolivia, Perú y Colombia-y distintas nacionalidades de Amé-

\section{FIGURA 3}

ORIGEN POR CONTINENTES Y PORCENTAJE DE POBLACIÓN EXTRANJERA RESPECTO AL TOTAL DE LA POBLACIÓN POR SECCIONES CENSALES EN EL BARRIO DE EL BESÒS I EL MARESME EN 2008

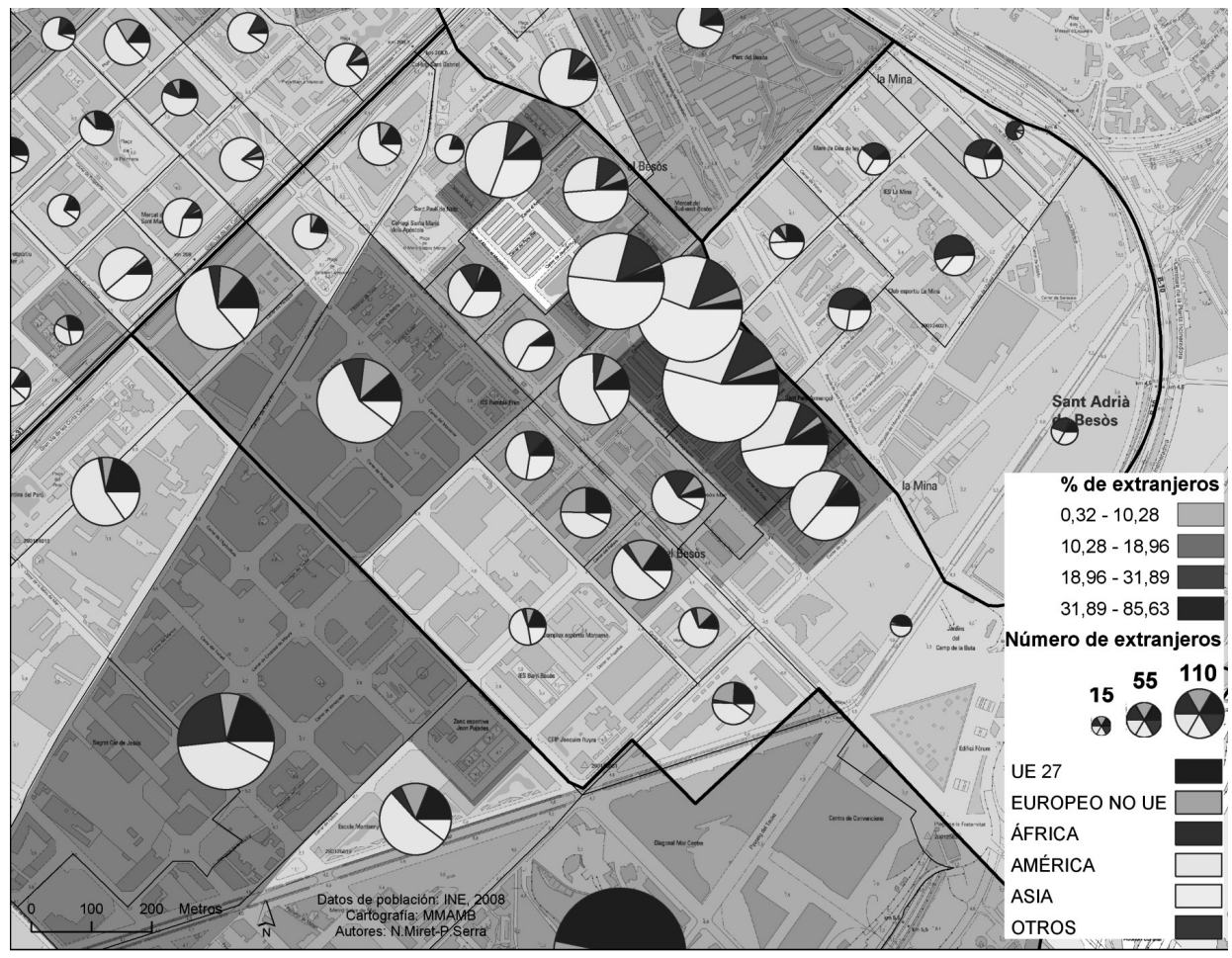

Fuente: elaboración propia a partir de Instituto Nacional de Estadística (datos estadísticos) y Mancomunitat de Municipis de l'Àrea Metropolitana de Barcelona (cartografía). 
rica Latina y de Europa del Este, configuran un espacio multicultural similar al de muchos barrios denominados «de inmigrantes» en Barcelona. Esta situación se confirma en 2012, salvo la disminución importante del colectivo ecuatoriano, que pierde 223 personas en nuestro barrio entre el padrón de 2008 y el de 2012, situación que se explica por una tendencia común a toda la ciudad de Barcelona, donde este colectivo empezó a marcharse a raíz de la crisis ${ }^{25}$.

Estos nuevos habitantes se ubican sobre todo en la parte nordeste de el Besòs i el Maresme, en aquellas secciones censales clasificadas como «zonas desfavorecidas» (Goñi, 2008), en donde los bloques residenciales no están aún tan renovados. Esta zona que se extiende entre la calle Alfons el Magnànim y el barrio vecino de La Mina también es la que nos señalaron en el trabajo de campo como la más conflictiva en los temas de las relaciones interétnicas.

La contribución de las poblaciones extranjeras, bien representadas en la mayoría de los grupos de edad correspondientes a la población activa ${ }^{26}$, también ayudó a la recuperación de la estructura de edad, además del saldo de población positivo en nuestro barrio de estudio. Aún así las personas mayores siguen estando ligeramente más representadas en el Besòs i el Maresme en comparación con la media municipal al menos hasta 2005, mientras que en 2011 la situación se invierte (tabla 1). Cabe mencionar aquí el problema del análisis estadístico a nivel de los barrios de Barcelona, que cambiaron sus delimitaciones territoriales a partir del año 2007 o 2008, interrumpiendo la continuidad de las series históricas de la estadística municipal. Por esta razón, puesto que los cambios en nuestra área de estudio no son muy relevantes, hemos preferido dejar los datos más antiguos, que subrayan el momento de cambio de rumbo demográfico, contrastados con el dato mas reciente ${ }^{27}$.

25 Este colectivo aumentó a nivel de la capital catalana hasta las 32.946 personas empadronadas en el 2004, para descender hasta 15.511 personas en el 2012. Parte de esta baja puede explicarse por variaciones residenciales en el interior de la región metropolitana, pero en muchos casos se trata de regresos - al menos temporales- al Ecuador.

${ }^{26}$ Hemos agrupado aquí los grupos de edades entre 25-39 años y 40-64 por ser las categorías de edad correspondientes a la población activa más representativas de la migración en sus primeros periodos.

${ }^{27} \mathrm{La}$ nueva división territorial de 73 barrios fue aprobada en diciembre del 2006 y los datos empiezan a ser difundidos con estos límites a partir del 2007, con cambios diferentes según los temas (ver www.bcn.cat o Garzarelli, 2010). En el caso de nuestro barrio, que pasó a denominarse «el Besòs i el Maresme» los cambios son mínimos — con solo algunas secciones censales que lo van a ampliar-, pero en el caso del vecino barrio de Poblenou, la nueva división territorial sanciona su división en cuatro barrios diferentes. 
TABLA 1

EVOLUCIÓN DE LA ESTRUCTURA DE EDAD EN BARCELONA

Y EN EL BESÒS I EL MARESME28

\begin{tabular}{l|cc|cc|cc|c|cr}
\hline & \multicolumn{2}{|c|}{$1991(\%)$} & \multicolumn{2}{c|}{$2001(\%)$} & $2005(\%)$ & $\begin{array}{c}2005(\% \\
\text { extranjero) }\end{array}$ & \multicolumn{2}{|c}{$2011(\%)$} \\
\cline { 2 - 9 } & $\begin{array}{c}\text { Besòs i } \\
\text { Maresme }\end{array}$ & Barcelona & $\begin{array}{c}\text { Besòs i } \\
\text { Maresme }\end{array}$ & Barcelona & \multicolumn{2}{c}{$\begin{array}{c}\text { Besòs i } \\
\text { Maresme }\end{array}$} & Barcelona & $\begin{array}{c}\text { Besòs i } \\
\text { Maresme }\end{array}$ & \multicolumn{2}{c}{$\begin{array}{c}\text { Besòs i } \\
\text { Maresme }\end{array}$} & Barcelona \\
\hline 0-14 años & 17,13 & 14,53 & 12,91 & 11,51 & 12,1 & 11,6 & 11,68 & 13,0 & 12,3 \\
15-24 años & 14,80 & 15,58 & 12,71 & 11,39 & 11,7 & 10,0 & 14,99 & 10,7 & 8,9 \\
25-64 años & 54,29 & 52,64 & 51,01 & 55,43 & 54,5 & 57,8 & 72,21 & 54,5 & 57,8 \\
$>65$ años & 13,78 & 17,37 & 23,37 & 21,67 & 21,7 & 20,5 & 1,12 & 18,4 & 20,8 \\
\hline
\end{tabular}

Nota: Solo disponemos de datos de grupos de edad de los extranjeros en el barrio para el año 2005.

Fuente: elaboración propia a partir de Ayuntamiento de Barcelona (2006) «Diagnòstic comunitari participatiu». Barcelona, Districte de Sant Martí y www.bcn.cat (para datos de 2011).

Además del rejuvenecimiento del barrio en términos de revitalización demográfica, el barrio permite estudiar los posibles cambios inducidos por la inmigración reciente. Es particularmente importante observar las consecuencias de esta transformación sobre los modos de vida y las estructuras espaciales. Nos fijamos a continuación en determinadas prácticas espaciales de los nuevos residentes, que pueden influir a corto o largo plazo sobre los procesos de revitalización.

¿LOS RECIÉN LLEGADOS RECONFIGURAN EL BARRIO?

\section{El papel de los comercios étnicos}

Al igual que muchos barrios construidos en los años sesenta, el de el Besòs i el Maresme ha sido diseñado principalmente alrededor de la función residencial. Si la inmigración más reciente de extranjeros ha cambiado profundamente la estructura de la población del barrio, también ha traído nuevos hábitos en el uso del espacio y nuevas actividades económicas. El Besòs i el Maresme no tiene tradición industrial, a diferencia del cercano barrio del Poblenou. Sólo

\footnotetext{
28 Solo disponemos de datos de grupos de edad de los extranjeros en el barrio para el año 2005.
} 
unas pocas empresas de transporte han sido localizadas. De los 1.322 expedientes de actividad económica en 2005 en el antiguo perímetro del barrio el Besòs i el Maresme ${ }^{29}, 138$ pertenecen a la industria, 35 a la construcción, pero la gran mayoría pertenece al sector de los servicios (559) o el comercio al por menor (345). Estos dos últimos sectores económicos, especialmente el del comercio al por menor, son importantes para comprender la lógica social del distrito, y su potencial de transformación. Eso es lo que tratamos de ver a través del trabajo de campo que llevamos a cabo en 2008 para observar el comercio de proximidad regido por emprendedores extranjeros. También nos interesaba recoger las percepciones de los vecinos «de siempre» en relación a los más recientes.

La presencia de numerosos comercios en una zona de elevada densidad de población es fundamental para la vitalidad del barrio que estudiamos. El comercio de proximidad fomenta la convivencia, los comerciantes se constituyen en «guardianes» de la seguridad y del civismo en el barrio, sus escaparates iluminados proporcionan puntos de referencia por la noche...: un barrio inseguro no es apto para la actividad comercial. Y, sobre todo, la desaparición de este comercio obliga a los habitantes, la personas mayores, por ejemplo, a desplazamientos suplementarios para su abastecimiento.

En los años 1990 Barcelona experimentó una crisis de los comercios minoristas, muchos de estos establecimientos cerraron sus persianas ${ }^{30}$. Entre 1995 y 2001, 665 comercios de la alimentación y del tabaco se cerraron en la capital catalana $^{31}$. Entre 1999 y 2005, pese a ser un periodo con numerosas aperturas de comercios a cargo de emprendedores extranjeros — como se ha documentado, al menos en el distrito de Ciutat Vella ${ }^{32}$ - el número de expedientes de comercio detallista en Barcelona desciende de 40.064 a 38.898 y de 386 a 345 en el Besòs i el Maresme. En cuanto a las actividades de alimentación el descenso en esos mismos años va de 12.802 a 12.530 y de 179 a 17433 .

No existe una correspondencia entre «actividades de alimentación» y comercios de alimentación, ya que un mismo comercio puede contener diferentes epígrafes de venta de productos de alimentación. En cualquier caso, en 2008 hemos comprobado la importancia de la presencia de las tiendas de alimentación regidas por extranjeros en nuestro barrio de estudio.

${ }^{29}$ Según el departamento de estadística del ayuntamiento de Barcelona (http://www.bcn.es/ estadistica/catala/dades/iae/a2005/sector/sczeg.htm).

${ }^{30}$ Carreras i Verdaguer, 1999.

${ }^{31}$ Carreras i Verdaguer, 2003.

32 Serra, 2006.

33 Datos procedentes de: http://www.bcn.cat/estadistica/catala/dades/economia/iae/index.htm 
«El retroceso del pequeño comercio frente a la implantación de grandes superficies comerciales, redunda en la simplicidad urbana, en la percepción de abandono de los espacios públicos y de inseguridad ciudadana, y en la desvertebración social que era evitada en gran medida por la existencia de funciones como la del pequeño comercio» (Alguacil Gómez, 2006).

A falta de un estudio pormenorizado - conviene además tener en cuenta la dificultad para obtener datos fiables en lo que se refiere a comercios en Cataluña-, pensamos que la presencia del comercio regido por extranjeros en nuestro barrio está teniendo un impacto positivo, es decir es un aspecto que nos anima a seguir trabajando en la línea de la hipótesis de la revitalización.

El comercio y los servicios parecen ser actividades que son normalmente desarrolladas por inmigrantes: en la Rambla Prim todavía se encuentran algunas tiendas típicas de la inmigración interna, como los bares «El Emigrante» — $\mathrm{y}$ «El Boquerón de Málaga» en el vecino barrio de La Pau- o la droguería «El Maño», que reflejan la historia comercial de esta zona tradicionalmente vinculada a la inmigración (Tatjer y Sintes, 2007). Hoy en día los comercios regentados por los inmigrantes extranjeros ${ }^{34}$ también se han implantado en el

TABLA 2

\section{COMERCIOS REGENTADOS POR EXTRANJEROS EN EL BARRIO DE} EL BESÒS I EL MARESME EN 2008

\begin{tabular}{|c|c|c|c|c|c|c|c|}
\hline $\begin{array}{c}\text { Tipo de comercio/ } \\
\text { Servicio } \\
\text { Nacionalidad del em- } \\
\text { prendedor }\end{array}$ & Pakistán & $\begin{array}{l}\text { India o } \\
\text { Bangla } \\
\text { Desh }\end{array}$ & $\begin{array}{l}\text { Colom- } \\
\text { bia }\end{array}$ & China & $\begin{array}{l}\text { Rep. } \\
\text { Domini- } \\
\text { cana }\end{array}$ & Ecuador & Total \\
\hline Locutorios y móviles & 11 & 1 & 1 & & & & 13 \\
\hline Restaurantes & 4 & & & 3 & & & 7 \\
\hline Carnicerías halal & 4 & & & & & & 4 \\
\hline Bares & 1 & 1 & & 3 & & 2 & 7 \\
\hline Alimentación & 6 & & & 1 & 1 & 1 & 9 \\
\hline Peluquerías & 3 & & & & & & 3 \\
\hline Bazares & & & & 3 & & & 3 \\
\hline Otros $^{1}$ & 4 & 1 & & 2 & & 1 & 8 \\
\hline Total & 33 & 3 & 1 & 12 & 1 & 4 & 54 \\
\hline
\end{tabular}

Nota: (1) Un supermercado de Bangla Desh; una tienda de videos, una agencia de viajes, una panadería y una farmacia de paquistaníes; un mayorista de comida china; y dos tiendas de ropa, de un chino y de un ecuatoriano.

Fuente: elaboración propia a partir del trabajo de campo realizado por Miret y Serra.

\footnotetext{
${ }^{34}$ Sobre el comercio étnico ver Light y Gold (2000) y Solé et al. (2007).
} 
barrio. La observación de este tipo de comercio (tabla 2) permite abordar tanto las formas de inserción de una parte de los inmigrantes en la ciudad, como también su impacto económico y social en la dinámica del barrio.

Los comercios administrados por emprendedores extranjeros en el Besòs i el Maresme en 2008 son 54. Todos en el barrio, excepto un mayorista de alimentación china, son minoristas. La mayoría están a cargo de paquistaníes (33) y chinos (12), predominio asiático que no sorprende, ya que es similar a lo que ocurre en otros barrios con numerosa población inmigrante y con muchos más comercios que en el Besòs i el Maresme como en Ciutat Vella en Barcelona o en l'Hospitalet de Llobregat — barrios de La Torrassa, La Florida,

FIGURA 4

\section{LOCALIZACIÓN DE LOS COMERCIOS Y SERVICIOS DE LOS INMIGRANTES SEGÚN TIPOLOGÍAS COMERCIALES EN EL BARRIO DE EL BESÒS I EL MARESME EN 2008}

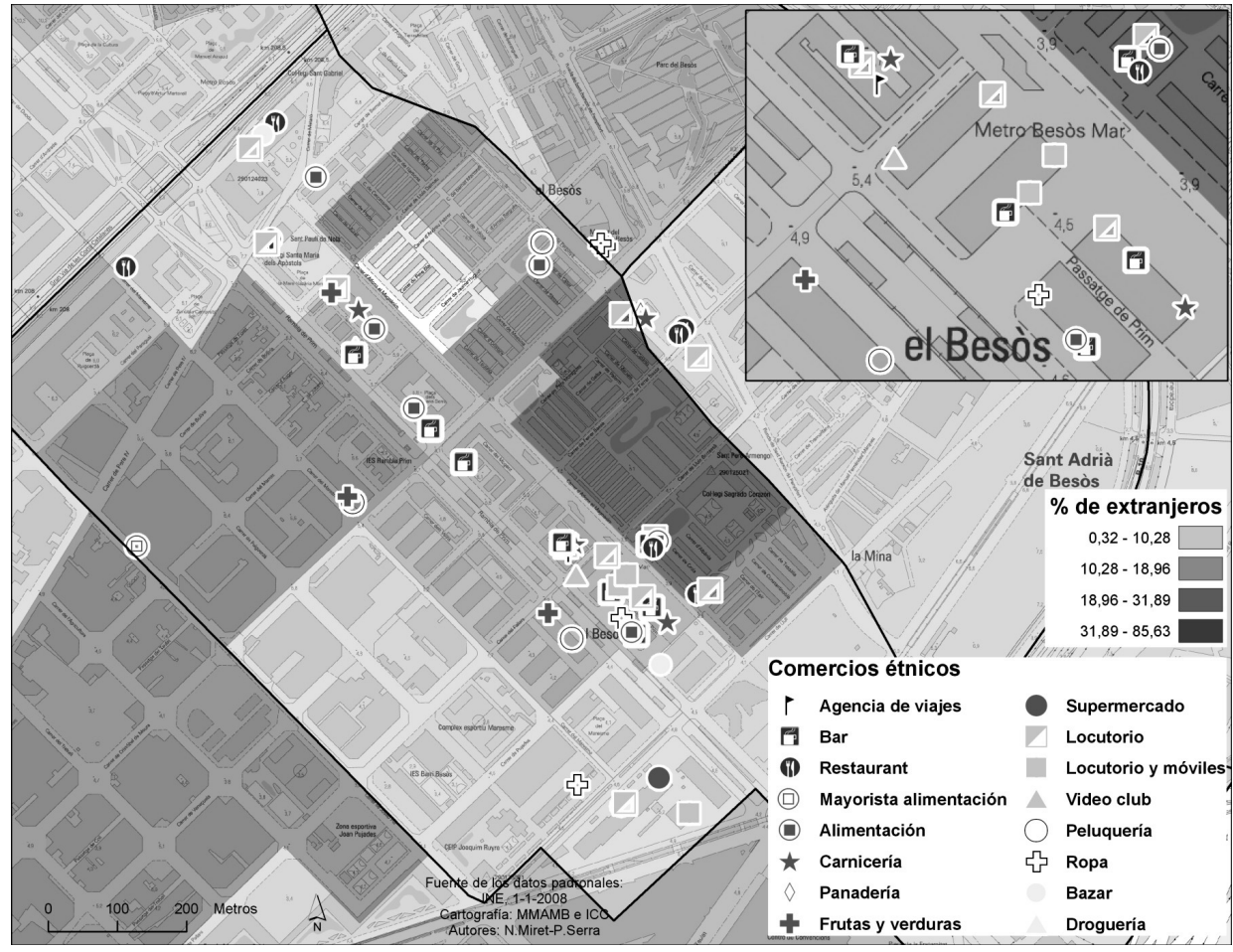

Fuente: elaboración propia a partir de Instituto Nacional de Estadística (datos estadísticos) y Mancomunitat de Municipis de l'Àrea Metropolitana de Barcelona (cartografía). 
Collblanc y Pubilla Casas-. Estos comercios se sitúan principalmente a lo largo de las principales calles del barrio: Rambla Prim, Alfons el Magnànim y Llull, con mayor concentración ( 24 de los 54), en un círculo de radio de 125 metros, entre la Rambla Prim y la calle Alfons el Magnànim (figuras 4 y 5).

La observación realizada nos permite tan solo avanzar hipótesis sobre el modo de gestión de estos comercios y su grado de organización étnica. Para Ma Mung (1992) el comercio étnico se define no sólo por el hecho de estar regido por emprendedores inmigrantes sino también por el uso y el apoyo que reciben por parte de redes de solidaridad étnica en relación a la financiación y al aprovisionamiento de las mercancías.

\section{FIGURA 5}

LOCALIZACIÓN DE LOS COMERCIOS Y SERVICIOS DE LOS INMIGRANTES SEGÚN NACIONALIDADES EN EL BARRIO DE EL BESÒS I EL MARESME EN 2008

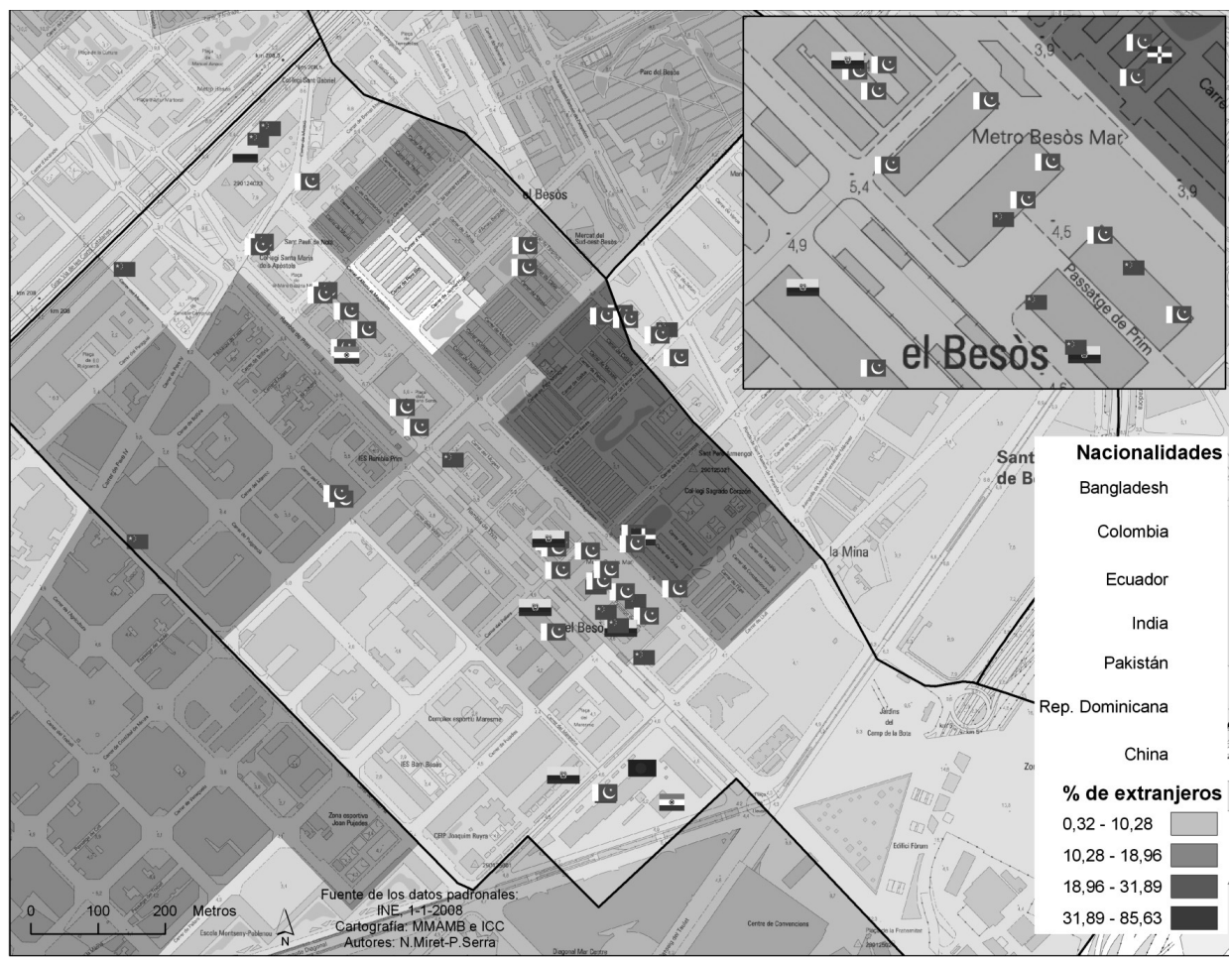

Fuente: elaboración propia a partir de Instituto Nacional de Estadística (datos estadísticos) y Mancomunitat de Municipis de l’Àrea Metropolitana de Barcelona (cartografía). 
En nuestro barrio la mayoría de los comercios son destinados al conjunto de la población, pero tienen a menudo una estrategia de «mise en scène ethnique» (Ma Mung, 1992), para atraer ciertos grupos. Determinados establecimientos pakistaníes utilizan por ejemplo la expresión «Pak» en el escaparate: los locutorios «Euro Pak III»y «Amar-Pak», el multicultural y multilingüe comercio de «EURO PAK ALIMENTACIÓ. PRODUCTES LATINOS, ASIATICS I ARABS», la peluquería «Ali Peluquería Pak», los dos bares pakistaníes «Pak Catalana». En otros casos los pakistaníes optan por escribir directamente su rótulo comercial en urdú, además de en castellano, como en un locutorio y en una carnicería en Alfons el Magnànim. En otro locutorio, uno de los grandes carteles exhibidos contiene las misteriosas siglas « $\mathrm{PCO} »$, solo inteligibles para los sudasiáticos del barrio, para quienes significa «Public Call Office». La carnicería de Hamad es en cambio bien explícita, con el rótulo «CARNICERIA ISLÁMICA», también en urdú.

Los ecuatorianos intentan en cambio atraer a clientes «latinos» con enseñas como «Alimentación Frutería Productos Latinos y Nacionales» y «Bar Latino» o a mostrar en el escaparate de la «Peluquería Dani» modelos de fotos de hombres y mujeres de aspecto latino con atractivos peinados.

Los chinos desarrollan estrategia más bien mixtas: algunos de ellos se comportan como servicios o comercios exóticos como «Restaurant Xinès Bona Sort» y «Basar Xinès»; otros, en cambio, son más discretos y no cambian las enseñas de los restaurantes y bares anteriormente en manos de españoles; en otros casos no exhiben rótulo, como en un bazar de la Rambla Prim o lo exhiben en bilingüe chino-castellano como el mayorista de la calle Josep Pla. En general pocos comercios son de orientación únicamente étnica como las carnicerías halal, "empresas especializadas en población inmigrante» (Solé et al., 2007, p. 95). En cualquier caso, el catalán suele ser el idioma menos usado.

Un bar paquistaní con la enseña «Pak shah» ostenta en el escaparate tres banderitas pintadas, la paquistaní, la catalana y la española encima del texto «Bienvenidos», y realmente es común que la clientela sea variada o al menos no exclusivamente étnica. En este caso, el local comercial cumple también con una función social, como lugar de vida común en el barrio, donde se intercambian noticias de la familia, y se comentan las informaciones que circulan dentro de las cadenas migratorias de cada grupo, función patente en los locutorios por ejemplo.

Estos pequeños emprendedores extranjeros se organizan por otra parte como los autóctonos en tiempos anteriores: tienen una sólida estructura familiar, especialmente entre los paquistaníes. La familia del Sr. Raza tiene tres co- 
mercios de alimentación a sólo 10 minutos los unos de los otros en el vecino municipio de Sant Adrià de Besòs. Dos hermanos paquistaníes tienen dos tiendas en el Besòs i el Maresme una al lado de la otra: una es restaurante y panadería, la otra es un comercio de alimentación. Sin embargo, existe una feroz competencia entre los locutorios paquistaníes en el Besòs i el Maresme: en un círculo de radio de tan solo 110 metros existen 7 establecimientos. Uno de los emprendedores, en la zona desde 2003, se muestra preocupado, más «negociante» que "pakistaní»: «el municipio de Barcelona debería impedir la apertura de nuevos locutorios, no vale la pena tener un comercio abierto sin clientes debido a la competencia». Este ejemplo de competencia «intra-étnica» muestra como, al fin y al cabo, el carácter comunitario no es siempre determinante en estas iniciativas que en muchos casos son de tipo individual, destinadas a promover la movilidad social como lo mostraron otras investigaciones (Solé et al. 2007, p. 27).

Todos esos establecimientos - excepto el mayorista chino- consisten en comercios y servicios de proximidad, hecho que influye particularmente en términos de cohesión social urbana y de reactivación económica: muchos son frecuentados también por los habitantes autóctonos, al menos puntualmente. La pequeña encuesta que realizamos en la calle en mayo de 2012 mostró un discurso ambiguo de cara a estos comercios. Los horarios amplios, que explican que a veces se utilicen estos comercios "para las urgencias», porque «el colmado de al lado está abierto a toda hora», y participen plenamente en la vida social del barrio. Estos horarios también se señalan como un problema en la convivencia, a causa de molestias que provocan: «la frutería cierra a las 12 tú te crees?, el bar hasta las 2 con música latina, pero en la escalera hay una familia latina pero todo bien» — mujer de 65 anos nacida en Salamanca, mayo 2009-.

También es interesante comprobar como el recurso a estos comercios «diferentes» esta poco asumido, ya que si la mayoría responde frecuentar sobre todo comercios españoles, también cita uno o dos comercios o de carne halal más barata, o de proximidad que sí frecuenta, si se le pregunta a continuación.

Los comercios étnicos son sólo una parte del comercio del barrio, pero estimamos sin embargo que son casi la mitad en el caso del sector alimentario. No es fácil comparar, sin embargo, el medio centenar de comercios étnicos de el Besòs i el Maresme con el número de negocios de variados orígenes en el conjunto del distrito de Ciutat Vella —306 en el año 2005 (Serra, 2006)—, que permite hablar allí de una «centralidad multiétnica» de mayor entidad (Serra, 2009). Sin embargo la densidad de comercios étnicos por habitante es similar 
en Ciutat Vella -27 comercios étnicos por cada 10.000 habitantes en el año 2005- y en el Besòs i el Maresme - 24 comercios étnicos por cada 10.000 habitantes en el año 2008 - ${ }^{35}$. Los emprendedores inmigrantes procuran reducir los costes de explotación - empleo de coétnicos o de familiares en condiciones inferiores a las «de mercado»-, y mantienen en el Besòs i el Maresme una oferta comercial de proximidad de interés sobre todo en relación a las tiendas de alimentación, mientras que existe saturación de locutorios. No hemos tenido oportunidad de actualizar el censo y de volver a entrevistar a los comerciantes desde esta crisis. Sabemos de algunos comercios que tuvieron que cerrar, pero también observamos que algunos solo cambiaron de «vitrina». Sería interesante observar cómo se reorganiza esta actividad y profundizar en los usos comerciales del conjunto de la población que también deben haber evolucionado desde nuestro principal trabajo de campo en 2008.

\section{Los espacios públicos y la movilidad}

Esta dinámica comerciante emergente también revela una cierta apropiación del territorio urbano por los residentes extranjeros, al mismo tiempo que permiten el contacto comunitario y el apoyo moral. En cuanto a la vida social y a las relaciones interétnicas, las entrevistas realizadas nos han permitido al menos considerar algunas hipótesis ${ }^{36}$. Para muchos de los nuevos residentes, esta zona representa la entrada en la ciudad europea con nuevos ritmos y prácticas, a los que deben adaptarse pese a proceder la mayoría de grandes ciudades. Las personas de las 14 nacionalidades presentes en el barrio no utilizan el espacio público de la misma manera. Uno de los aspectos de nuestras conversaciones se centró en las representaciones del territorio urbano y sobre los modos de apropiación del barrio. El resultado es una doble tendencia de anclaje en lo local y la frecuentación regular a otros barrios de inmigración. El fuerte anclaje local es una tendencia compartida de manera muy evidente por todos los habitantes del barrio, cualquiera sea su origen o edad. Este anclaje

35 Proporción que volvemos a encontrar en otros barrios metropolitanos: Collblanc, La Torrassa, Pubilla Casas, La Florida, en l'Hospitalet de Llobregat, con 25 comercios por cada 10.000 habitantes en el año 2007.

36 Hemos realizado cuatro entrevistas a inmigrantes extranjeros adultos en el Besòs i el Maresme, complementadas con numerosas observaciones directas. Nos apoyamos también sobre una treintena de entrevistas realizadas en el mismo periodo en otros barrios periféricos, sobre todo en l'Hospitalet de Llobregat. 
local se explicaría como en muchos casos por la proximidad física de las redes sociales y familiares. En la encuesta preguntamos por la localización residencial de los familiares, de lo cual se desprendía que aparte de una gran mayoría -23 parientes - que residen en el extranjero, lo que corresponde a las familias de inmigrantes, 16 - de los inmigrantes o nativos- mencionaron miembros de la familia residentes en el mismo barrio, y 29 en el resto de la ciudad. En parte esto puede explicar que tienen la mayoría de su vida social y de sus actividades en el barrio o a proximidad, sin mencionar casi nunca los otros barrios de la ciudad, ni siquiera el mismo centro de Barcelona cuando se les pregunta por sus actividades recientes de compras ocio o relaciones sociales. Tres sesiones de entrevistas colectivas en aulas de acogida de jóvenes inmigrantes en el instituto de enseñanza secundaria del barrio ${ }^{37}$ permiten subrayar la existencia de algunos espacios públicos más apreciados para el encuentro de jóvenes, como la práctica deportiva en una pista pública, la vida social en determinados centros comerciales vecinos y la playa cercana. Pero en ningún caso aparecen lugares propiamente asimilables a un grupo especifico, con la excepción de una persona que menciona una sala de baile «latino» en el barrio Fabra i Puig.

Por otro lado, los desplazamientos familiares los realizan principalmente a otros barrios, especialmente a la ciudad de l'Hospitalet de Llobregat, junto a Barcelona. Las salidas nocturnas tienen en muchos casos como destino tanto otros barrios de inmigrantes como algunos restaurantes étnicos, pero nunca son muy destacadas en los entrevistas. Algunas mujeres, a causa de su trabajo en el servicio doméstico ${ }^{38}$, circulan cotidianamente y tienen un mejor conocimiento de la ciudad, aunque, al igual que sus hijos recién llegados con los que hablamos en el instituto, identifican sólo las estaciones de metro que usan habitualmente. Cuando pueden las mujeres prefieren pasear y desplazarse a su lugar de ocio a pie. El coste económico es citado como principal razón, pero creemos que hay otras razones, como un cierto temor a lo desconocido. Entre los más jóvenes —algunos de ellos llegaron muy pequeños al barrio-, a partir de la adolescencia se insertan en otras redes sociales no étnicas del barrio y de la ciudad; se percibe así una «normalización de las prácticas espaciales»:

${ }^{37}$ Entrevistas realizadas en tres sesiones con 16 jóvenes en una aula de catalán para nuevos alumnos del instituto del barrio (noviembre de 2007).

38 Una gran mayoría de mujeres extranjeras ejercen su trabajo en el servicio doméstico, el 39,4\% en 2005 según las estadísticas de la Encuesta de Población Activa (Domingo y Gil, 2007, p. 6). 
como los habitantes autóctonos, ya conocen bien las posibilidades que ofrece la ciudad y se desplazan a distintas partes. Es el caso de Adelina (Ecuador) que frecuenta esencialmente el barcelonés barrio de Gràcia con sus amigos estudiantes —entrevista en mayo de 2009-.

En cuanto a la organización del espacio social en el Besòs i el Maresme se han desarrollado dos ejes: el de la Rambla de Prim y el de la calle Alfons el Magnànim. El primero es el más agradable para caminar, ya que está flanqueada de árboles y bancos y vemos muchas personas mayores y mujeres con sus hijos pequeños, ya sean autóctonas o inmigrantes (fotografía 1).

Otras áreas de relación son la cancha pública de baloncesto en la Rambla Prim, donde jóvenes latinoamericanos juegan a mediodía o por las tardes. El eje de la calle Alfons el Magnànim ofrece una cara muy distinta: tiene menos tráfico, la calzada es estrecha y se encuentra más próximo al barrio de La Mina - en el municipio de Sant Adrià de Besòs-, con una alta proporción de población gitana, y algunos grupos de minoría gitana rumanos, cuya presencia en ese lado de la calle es notoria. La calle tiene árboles y bancos y acera ancha para pasear, pero el conjunto no es atractivo, algunas personas inactivas vagan por la calle, las aceras y los edificios ofrecen signos de degradación, hay graffitis, la estación del sistema «Bicing» — servicio municipal de alquiler barato de bicicletas para desplazamientos breves- ha tenido que ser retirada, porque las bicicletas estacionadas resultaron dañadas —en la Rambla Prim sí que hay una estación-. Los denominados «centros comerciales», pequeños espacios situados al pie de los edificios residenciales en la calle de Alfons el Magnànim para media docena de negocios, tienen un aire abandonado, en las paredes con azulejos faltan algunas piezas. Aún así algunas de las tiendas han sido renovadas por emprendedores inmigrantes (fotografía 2). A pesar del cierto abandono, y de cierta imagen de marginalidad, los espacios públicos son muy utilizados en Alfons el Magnànim. Es un lugar de circulación, próximo a las escuelas, y su aspecto mejoró con el «Pla de Millora de Barris», que dedicó una tercera parte de las inversiones a este apartado de espacios públicos y espacios verdes.

\section{Los centros de culto}

Los centros de culto del barrio también desempeñan un papel en la acogida. Son cuatro: dos iglesias católicas, Sant Pau de Nola —en funcionamiento desde 1968 - y Sant Pere Armengol —construida en 1946 para la atención pastoral de los residentes de los barrios marginales del Camp de la Bota-y 
FIGURA 6

CENTROS DE CULTO Y USO DEL ESPACIO EN EL BARRIO DE EL BESÒS I EL MARESME DE BARCELONA

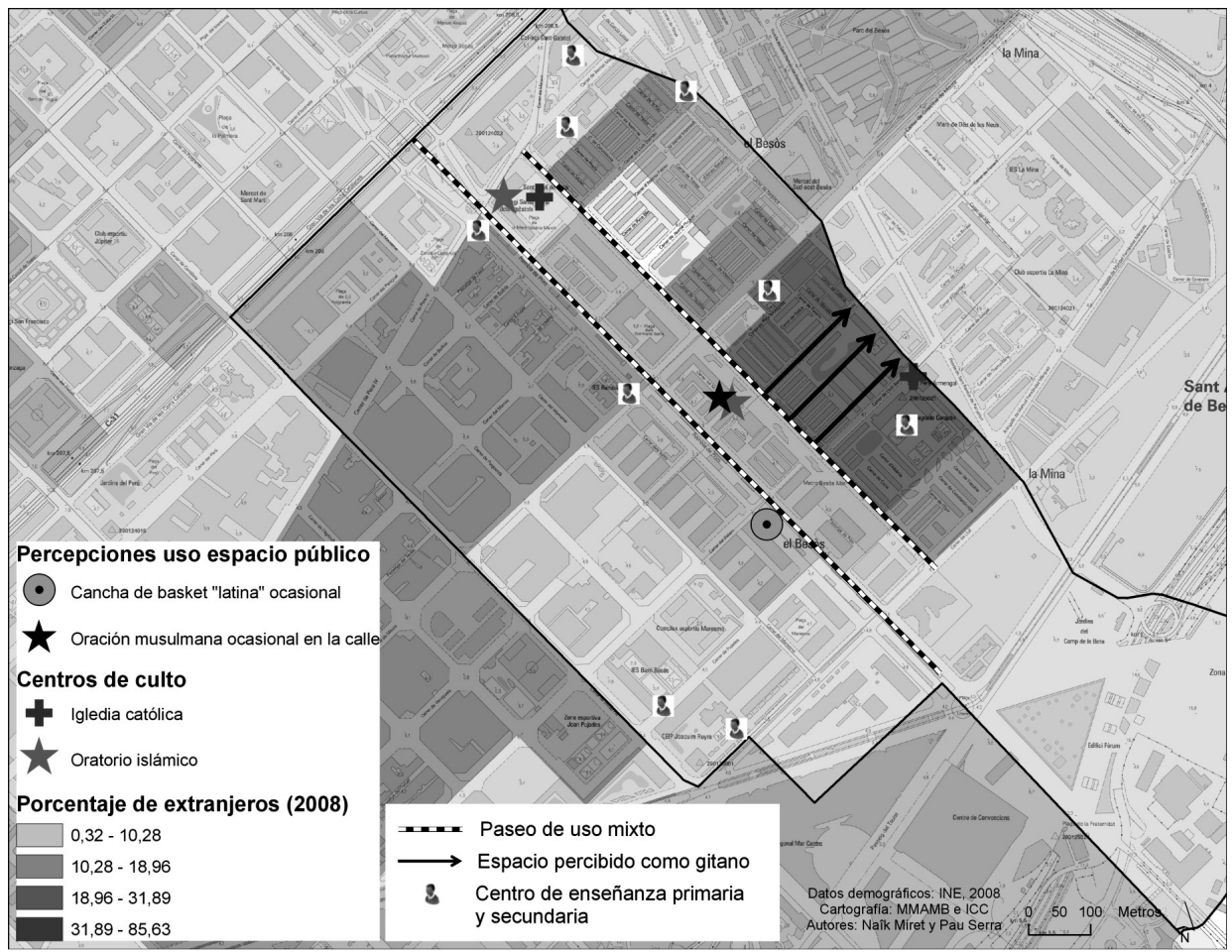

Fuente: elaboración propia a partir de Mancomunitat de Municipis de l'Àrea Metropolitana de Barcelona (cartografía).

dos pequeños oratorios musulmanes — modestos locales en planta baja- (figura 6). No es extraño que haya dos mezquitas en un barrio donde la población musulmana, sobre todo la paquistaní, es numerosa, pero una de las mezquitas está en un lugar tan discreto, junto a la plaza de la Mare Nazària March, donde precisamente se sitúa la parroquia católica de Santa Maria del Apòstols, que dos señoras que viven muy cerca decían que desconocían su existencia, pese a la visible «procesión» de pakistaníes que se acercan a esa mezquita el viernes a mediodía. 


\section{La convivencia social}

Parece como si la gente se adaptara rápidamente a los nuevos espacios públicos, utilizando los espacios disponibles como lugar de encuentro. La mayoría de los comercios étnicos, sobre todo los locutorios, se convierten en lugares de relaciones entre personas de distintos orígenes y para las de la misma nacionalidad, o de la misma cadena migratoria. Pero se observa que las representaciones del cambio social en el discurso de la gente son en ocasiones negativas, desde los tonos claramente xenófobos hasta declaraciones más matizadas, teñidas de un cierto racismo. Una anciana residente del barrio dice que fue al centro de la ciudad de Barcelona, Ciutat Vella, donde vio «muchos comercios de inmigrantes que infectan ese barrio... ahora es mi barrio el que ya está infectado» — mujer, nacida en Soria, 62 años, mayo 2009—. En cambio, un hombre más joven dijo que no tenía nada contra los comerciantes paquistaníes en la zona, que incluso la relación con los paquistaníes residentes en su edificio es mejor que con otros extranjeros. Empleados municipales de la limpieza de la calle de Alfons el Magnànim señalan que «hay demasiados inmigrantes», refiriéndose a los gitanos rumanos. Entre los comerciantes autóctonos existen también reacciones positivas y otras negativas respecto a los negociantes inmigrantes.

Estas situaciones han sido observadas en otros barrios de características similares, donde los comerciantes españoles y «los vecinos autóctonos perciben la llegada de inmigrantes en grandes números como un proceso de degradación de su barrio» (González Enríquez et al., 2005, p. 22; Serra, 2008). Las expresiones de xenofobia están probablemente relacionadas con la rapidez con que ha ocurrido el cambio social. Nuestro estudio exploratorio no ha revelado en cambio tensiones o conflictos como los que se han producido en otros barrios populares de otras ciudades dentro y fuera de Cataluña ${ }^{39}$, sino más bien los esfuerzos de algunos agentes sociales para considerar la nueva realidad de la inmigración extranjera. Por esta razón, nació el plan de convivencia, «Pla Comunitari de barris de Besòs ${ }^{40}$, que aspira a mejorar la sociabilidad a través de las iniciativas de varios actores. La escuela, por ejemplo, es un ámbito donde se colabora en la integración de los recién llegados, los equipos docentes están tratando de ayudar a las familias a que se familiaricen con el barrio.

${ }^{39}$ Según los testimonios de varios conocedores del barrio recogidos durante nuestras entrevistas. El libro de Moreras (2009) se centra en conflictos relacionados con las nuevas mezquitas en barrios de localidades catalanas.

${ }^{40}$ Fuente: «Diagnòstic comunitari participatiu», del Ajuntament de Barcelona, 2006. 
La escuela del Sagrat Cor —construida en 1964 en el barrio por las religiosas, cuando todavía no existía escuela pública-, cerca de la Mina, exhibía en 2009 un gran cartel en su fachada, con el texto en catalán «Fem de la nostra escola la casa de tots» - Hagamos de nuestra escuela la casa de todos- Otros actores involucrados, como el sacerdote de la parroquia católica de Santa Maria del Apòstols felicita a los musulmanes de la vecina mezquita —a tan sólo cincuenta metros- el Ramadán, mientras que éstos felicitan a los católicos la Navidad. La asociación Cáritas instaló en la misma parroquia un lugar de acogida temporal de indocumentados de todos los orígenes, y esa parroquia celebra cada mes una «Misa Latina», de acuerdo con las tradiciones religiosas más festivas de determinadas poblaciones de América Latina. Sin embargo los participantes destacaron la baja participación de las familias inmigrantes, cuya instalación en el barrio es tal vez aún demasiado reciente o precaria como para dedicar tiempo a estas actividades.

\section{CONCLUSIONES}

Para concluir la presentación de esta investigación exploratoria, nos parece evidente que los nuevos residentes relacionados con la elevada inmigración extranjera en los últimos años están contribuyendo a la reconfiguración del barrio de el Besòs i el Maresme, en paralelo con el proceso de renovación urbana iniciado por las administraciones públicas en el distrito.

No hemos observado en directo el conflicto que tuvo lugar en enero de 2012 en el barrio y que despertó muchos temores a tensiones racistas. Un joven senegalés, fue asesinado a tiros por miembros de una familia gitana, lo que muy rápidamente fue interpretado como violencia interétnica. A través de la prensa, que precipitadamente dejó planear la sombra de los eventos de las banlieues en Francia en 2005, podemos observar como, al contrario, después de unas manifestaciones de protesta, se fue apaciguando el clima gracias a la intervención de vecinos y profesionales del Ayuntamiento y del Estado, que consiguieron «normalizar» este crimen: «Las asociaciones de gitanos y senegaleses de Cataluña escenificaron ayer su rechazo a la violencia y su apuesta por la convivencia tras el asesinato a tiros, el pasado martes, de Ibrahima Dyey. Las entidades coincidieron al exigir justicia — los cuatro detenidos son miembros de una familia de etnia gitana-y negaron que haya problemas entre los dos colectivos». (El País, 5 enero 2012).

Las tensiones interétnicas observadas, al igual que en muchos barrios desfavorecidos de otras ciudades españolas, necesitan una cierta vigilancia. El de- 
safío de los poderes públicos es beneficiarse de los modelos urbanos de otros países: ¿cómo evitar reproducir la «norma» europea de barrios de vivienda social, donde la presencia extranjera está fuertemente asociada con una espiral de degradación física y de exclusión social? ¿En otras palabras, nos aproximamos a un modelo de barrio «en crisis» «a la francesa» o a un proceso innovador donde los actores inmigrantes juegan un papel activo y simbólico en la capacidad de atracción de nuevas personas de que dispone el parque de viviendas, en un entorno mejorado o en vías de ser mejorado, en el contexto de modernización y mejora urbana de este entorno?

Los análisis de la prensa catalana en el inicio de la crisis económica global se mostraban esperanzados respecto a que los inmigrantes irían ocupando el exceso de recientes viviendas construidas no ocupadas en España y así contribuirían en la resolución de la crisis inmobiliaria y económica española. Sin embargo, los inmigrantes también han sido el colectivo más afectado por el desempleo desde 2008. Aún así, el hecho de que algunos hayan retornado a su país de origen no invalida el interés de nuestras interrogaciones, sobre todo en relación a los extranjeros que se están instalando de forma permanente en los barrios de la ciudad.

Fecha de recepción: 22/07/2011

Fecha de aceptación: 25/05/2012

\section{BiBLIOGRAFíA}

Ajuntament de Barcelona (2006): "Diagnòstic comunitari participatiu". Barcelona, Districte de Sant Martí.

Ajuntament de Barcelona (2012): Informes estadístics: La població estrangera a Barcelona. Barcelona, Departament d'Estadística. Disponible en: www.bcn.cat (Fecha de consulta 09/09/2012).

Alberch i Fugueras, R. (1997-2000): Els Barris de Barcelona. Barcelona, Enciclopèdia Catalana y Ajuntament de Barcelona.

Algaba, Antonio (2003): "La discriminación en el acceso al mercado de la vivienda: las desventajas de la inmigración. Novedades y permanencias". Scripta Nova. Revista electrónica de geografía y ciencias sociales, VII/146. Disponible en: http://www.ub.es/geocrit/sn/sn-146(060).htm (Fecha de consulta: 11/10/2010).

Alguacil Gómez, J. (2006): "Barrios desfavorecidos: diagnóstico de la situación española", en F. Vidal Fernandez: Exclusión social y el estado del bienestar en España. V Informe Fuhem de políticas sociales y estado de bienestar. Barcelona, Icaria Editorial, pp. 155-168. 
Arbaci, S. (2008): "Hacia la construcción de un discurso sobre la inmigración en las ciudades del sur de Europa. La política urbanística y de vivienda como mecanismos estructurales de marginación étnica residencial". ACE: Architecture, City and Environment, 8, pp. 11-38.

Bayona, J. y Domingo, A. (2004): "Determinantes sociodemográficos en la localización espacial de la población extranjera en Barcelona", en: IV Congreso sobre la Inmigración en España. Girona, 10-13 noviembre de 2004. Incluido en las actas publicadas en CD (ISBN: 84-8458-206-X).

Beaverstock, J. V., Smith, R. G. y Taylor, R. G. (1999): “A Roster of World Cities". Cities, 16/6, pp. 445-458. Disponible en: http://www.lboro.ac.uk/gawc/rb/rbl1.html (Fecha de consulta: 11/10/2010).

Bohigas, O. (1985): Reconstrucció de Barcelona. Barcelona, Edicions 62.

Botey Vallès, J. (1986): 54 relats d'immigració. Barcelona, Centre d'estudis de l' Hospitalet de Llobregat, Diputació de Barcelona.

Brun, J. y Bonvalet, C. (2002): "Etat des lieux des recherches sur la mobilité résidentielle en France", en J. P. Levy y F. i Dureau: Laccès à al ville. Les mobilités spatiales en question. París, l'Harmattan, pp. 15-64.

Carreras i Verdaguer, C., (coord.) (1999): Els eixos comercials metropolitans. Barcelona, Ajuntament de Barcelona, Comerç, Consum i Turisme.

Carreras i Verdaguer, C., (coord.) (2003): Atles comercial de Barcelona. Barcelona, Ajuntament de Barcelona y Cambra de Comerç de Barcelona.

Colectivo IOE (2006): Inmigración y vivienda en España. Madrid, Ministerio de Trabajo y Asuntos Sociales.

Delgado, M. (2005): Elogi del vianant, del «model Barcelona» a la Barcelona real. Barcelona, Edicions de 1984.

Domingo Valls, A. y Gil Alonso, F. (2007): "Immigration et évolution de la structure de la main-d'oeuvre au Sud de l'Union européenne". Population, 62/4, pp. 825-845.

Domingo Valls, A., Lopez Gay, A. y Bayona Carrasco, J. (2004): "Impacto demoespacial de la internacionalización de los flujos migratorios en la ciudad de Barcelona". Migraciones, 16, pp. 157-198.

El Periódico (2012): "Los vecinos del Besòs denuncian la inflexibilidad de la ley de barrios". 9 de abril, pp. 30.

Eseverri Mayer, C. (2010): "Jóvenes en la tierra de nadie, hijos de inmigrantes en un barrio de la periferia de Madrid". Tesis doctoral. Universidad Complutense de Madrid, Instituto Universitario Ortega y Gasset. Madrid.

Federació d'Associacions de Veïns i Veïnes de Barcelona (2006): El barri, espai de conviviencia. Barcelona, Editorial Mediterrània, Quaderns de Carrer.

Fullaondo, A. (2008): "Inserción y lógica residencial de la inmigración extranjera en la ciudad. El caso de Barcelona". Cataluña, Universidad Politécnica de Cataluña, Departamento de Construcciones Arquitectónicas (Tesis doctoral).

Garzarelli, S. (2010): "La evolución de la población de nacionalidad extranjera en el barrio del Besós". Barcelona, Universidad Autónoma de Barcelona, Departamento 
de Geografía de la Universidad Autónoma de Barcelona - Centro de Estudios Demográficos, Bellaterra (Cerdanyola del Vallès) (Memoria de master).

González Enríquez, C. y Alvarez-Miranda, B. (2005): Inmigrantes en el barrio. Un estudio cualitativo de opinión pública. Madrid, Ministerio de Trabajo y Asuntos Sociales.

Goñi, B. (2008): "Identificación, localización y caracterización de las secciones censales desfavorecidas de la Región Metropolitana de Barcelona". Scripta Nova. Revista Electrónica de Geografía y Ciencias sociales, XII/272. Disponible en: http://www.ub.es/geocrit/sn/sn-272.htm (Fecha de consulta: 11/10/2010).

Hoyt, H. (1939): The Structure and Growth of Residential Neighborhoods in American Cities. Washington D.C., Federal Housing Administration.

Instituto Nacional de Estadística (2009): Encuesta Nacional de Inmigrantes 2007: una monografía. Madrid, Instituto Nacional de Estadística.

Leal, J. (2002): "Segregación social y mercados de la vivienda". Revista Española de Sociología, 2, pp. 59-75.

Light, I. y Gold, S. (2000): Ethnic Economies. San Diego, Academic Press.

Ma Mung, E. (1992): "L'expansion du commerce ethnique: Asiatiques et Maghrébins dans la région parisienne". Revue Européenne des Migrations Internationales, 8/1, pp. 39-59.

Miret, N. (2009a): "Inmigración y metropolización en Barcelona"; en A. Pedreño Canovas, y F. Torres Pérez (coords.): Migraciones internacionales, contextos y dinámicas territoriales). Áreas, Revista Internacional de Ciencias Sociales, 29. Murcia, Universidad de Murcia, pp. 103-116.

Miret, N. (2009b): "Les déterminants de l'insertion résidentielle d'une immigration récente: les Andins à Barcelone". Migrants et société, 21/125, pp.129-145.

Miret, N. y Serra del Pozo, P. (2008): "Potentiels de transformation des quartiers populaires de la banlieue de Barcelone à travers les pratiques socio-résidentielles et économiques de l'immigration latino-américaine récente", en Périphéries urbaines entre normes et innovations. Les villes du sud de l'Europe. Coloque ADES, Bordeaux (Francia), du 11 au 14 junio 2008.

Módenes, J. A. (2001): "Relacions socioterritorials i mobilitat residencial a l'àrea de Barcelona". Revista Catalana de Sociología, 14, pp. 43-56.

Moreras, J. (2009): Una mesquita al barri. Conflicte, espai públic i integració urbana dels oratoris musulmans a Catalunya. Barcelona, Transits y Fundació Jaume Bofill.

Portes, A. y Stepick, A. (1993): City on the Edge: The Transformation of Miami. Berkeley y Los Angeles. Los Angeles, University of California Press, Ltd.

Roca i Albert, J., (ed.) (1994): El futur de les perifèries urbanes. Canvi econòmic i crisis social a les metròpolis contemporànies. Barcelona, Institut de Batxillerat "Barri Besòs".

Rumbaut, R. G. (1999): “Assimilation and Its Discontents: Ironies and Paradoxes”, en C. Hirschman, J. Dewind y P. Kasinitz (eds.): The Handbook of International Migration: The American Experience. New York, Russell Sage Foundation, pp. 172-195. 
Sargatal Bataller, A. (2001): "Gentrificación e inmigración en los centros históricos: el caso del barrio del Raval en Barcelona". Scripta Nova, 66/94. Disponible en: http://www.ub.es/geocrit/sn-94-66.htm (Fecha de consulta: 11/10/2010).

Serra del Pozo, P. (2006). El comercio étnico en el distrito de Ciutat Vella de Barcelona. Barcelona, Fundació La Caixa. Disponible en: http://pauserra.files.wordpress.com/ 2008/08/pau-serra-el-comercio-etnico-en-el-distrito-de-ciutat-vella.pdf (Fecha de consulta: 11/10/2010).

Serra del Pozo, P. (2008). "Las asociaciones de comerciantes como actores para la convivencia: el caso de Ciutat Vella (Barcelona)", en R. Zapata-Barrero y G. Pinyol (eds.): "Los gestores del proceso de inmigración. Actores y redes de actores en España y Europa". Barcelona, CIDOB, pp. 199-219. Disponible en: http://www.cidob.org/es/content/download/7250/72346/file/11_serra.pdf (Fecha de consulta: 12/10/2010).

Serra del Pozo, P. (2009): "Los procesos geográficos de concentración en las centralidades étnicas". Revista Internacional de Organizaciones, 2, pp. 89-108. Disponible en: http://revista-rio.org/index.php/revista_rio/article/view/24/23 (Fecha de consulta: 19/05/2012).

Solé, C. (1981): La integración sociocultural de los inmigrantes en Cataluña. Madrid, Centro de Investigaciones Sociológicas.

Solé, C., Parella, S. y Cavalcanti, L. (2007): El empresariado inmigrante en España. Barcelona, La Caixa.

Tatjer, M. (2005): "La vivienda obrera en España de los siglos XIX y xx: de la promoción privada a la promoción pública (1853-1975)". Scripta Nova. Revista electrónica de geografía y ciencias sociales, IX/194 (23). Disponible en: http://www.ub.es/geocrit/sn/sn-194-23.htm (Fecha de consulta: 11/10/2010).

Tatjer, M. y Sintes, M. (2007): El Comerç a Sant Martí: dels establiments centenaris als nous eixos comercials. Barcelona, Ajuntament de Barcelona, Districte de Sant Martí.

Terrones, A. (2008): "Immigració i habitatge: els canvis en les pautes d'exclusió residencial". Fundació Nous Horitzons, 190/47, pp. 42-47.

\section{RESUMEN}

En este trabajo se observan las pautas de la instalación residencial de la nueva inmigración extranjera, los patrones de implantación de comercios regentados por emprendedores inmigrantes, así como ciertos usos del espacio privado y público y la movilidad en y desde el barrio de el Besòs i el Maresme. El espacio vivido por los extranjeros contiene elementos de cambio urbano que se añaden a las dinámicas urbanísticas impulsadas desde las administraciones públicas. El Besòs i el Maresme permite no solo evaluar tendencias comunes a muchos barrios populares españoles que conocen actualmente la misma etapa de desarrollo, sino que también ofrece una posibilidad de análisis en términos de revitalización urbana por su localización en el entorno inmediato del mayor espacio de cambio urbanístico en el nordeste de la capi- 
tal catalana, aunque no se ignoran en el trabajo procesos contradictorios que apuntan hacia la marginación social. Este texto se basa en trabajo de campo realizado por los autores en 2007-2009.

Palabras Clave: inmigración extranjera; espacios vividos; barrios populares; revitalización urbana; marginación social.

\section{Abstract}

The patterns of residential installation of the new foreign immigration, the patterns of implementation of businesses run by immigrant entrepreneurs, as well as certain uses of private and public space and mobility to and from the neighborhood of el Besòs i el Maresme are contemplated in this paper. The lived space by the foreign immigrants contains elements of urban change that are added to the urban dynamics promoted by the public governments. El Besòs i el Maresme not only allows for the assessment of trends common to many Spanish popular neighborhoods that meet now the same stage of development, but it also offers a possibility of analysis in terms of urban revitalization by its location in the immediate vicinity of the largest space of urban change in the northeast of the Catalan capital, although the contradictory processes at work that point to the social marginalization are not ignored. This text is based on fieldwork done by the authors in 2007-2009.

KEY WORDS: foreign immigration; lived-in areas; working-class neighbourhoods; urban revitalization; social alienation.

\section{RÉSUMÉ}

Ce travail présente les formes d'installation résidentielle de la nouvelle immigration étrangère, les formes d'implantation des commerces tenus par des entrepreneurs immigrants, ainsi que certains usages de l'espace public et privé et la mobilité vers le quartier de el Besòs i el Maresme et à partir de celui-ci. L'espace vécu par les étrangers contient des éléments de transformation urbaine qui s'ajoutent aux dynamiques urbanistiques impulsées par les administrations. El Besòs i el Maresme permet non seulement d'évaluer les tendances communes à de nombreux quartiers populaires en Espagne qui connaissent actuellement la même étape de développement, mais offre également une possibilité d'analyse en termes de revitalisation urbaine par sa localisation dans l'entourage immédiat du principal espace de renouvellement urbain au nord-est de la capitale catalane, bien que certains processus contradictoires qui révèlent une tendance à l'exclusion sociale ne soient pas ignorés dans ce travail. Ce texte repose sur une étude de terrain menée par les auteurs en 2007-2009.

MoTS-CLÉS: immigration étrangère; espaces vécus; quartiers populaires; renouvellement urbain; exclusion sociale. 